\title{
LA SEMIÓTICA EN EL PERÚ
}

\section{Enrique Ballón Aguirre}

\author{
Arizona State University
}

\section{EVOLUCIÓN DE LOS ESTUdIOS SEMIÓTICOS EN EL PERÚ}

En el transcurso de los más de treinta años de estudios semióticos realizados en el Perú, pueden distinguirse tres etapas en secuencia más o menos clara: una primera, que va de los años 1970 a 1975, que se caracteriza por la implantación de la disciplina en los centros de estudios superiores peruanos; la segunda, comprendida entre 1975 y 1990, de afianzamiento investigatorio y difusión internacional; por último, la tercera etapa que abarca la década final del pasado siglo y la proyección futura de estos estudios cada vez más adecuados a la comprensión de los objetos de conocimiento semiótico propios de la multilingüe y pluricultural sociedad peruana ${ }^{1}$.

Durante la etapa inicial, merced a la coyuntura política y académica del comienzo de la década de los 70 que propició una renovación de programas y cursos en las universidades peruanas, se facilitó la difusión de los primeros

\footnotetext{
1 El informe actual sigue, en lo principal, otros dos recuentos precedentes sobre la actividad semiótica peruana, cf. E. Ballón Aguirre (1986 y 1990).
} 
conocimientos semióticos en el Programa Académico de Lingüística, Literatura y Periodismo de la Universidad Nacional Mayor de San Marcos de Lima y en el Programa de Letras y Ciencias Humanas de la Pontificia Universidad Católica del Perú ${ }^{2}$. Sin embargo, el entorno académico recalcitrante a los cambios y aliado a la crítica literaria tradicional —abanderada por Luis Alberto Sánchez y Antonio Cornejo Polar ${ }^{3}$ - asumió una actitud beligerante contra cualquier intento de renovar las viejas posiciones historicistas, positivistas, populistas y estilísticas. Para estos espíritus intuitivos y locuaces, el metalenguaje semiótico, aplicado a los objetos de conocimiento literario peruano, resultaba «excesivamente riguroso» y su rendimiento interpretativo de poca monta, comparado con los comentarios sin cabestro disciplinario ${ }^{4}$. En medio de todo, con la creación del curso «Análisis semiolingüístico del discurso», en el Programa de Lingüística de la Universidad Nacional Mayor de San Marcos en $1975^{5}$, se oficializó la enseñanza de esa materia y su vigencia, ejemplo que siguieron pronto la Universidad de Lima al hacer intervenir algunos criterios de semiótica general en el Programa de Ciencias de la Comunicación y el Programa de Ciclo Básico, la Pontificia Universidad Católica en ciertos cursos de los programas de literatura y antropología e igualmente la Escuela Nacional de Bellas Artes, adscrita al Instituto Nacional de Cultura del Perú, que incluyó dichos conocimientos en su programa regular de enseñanza. Por último, el Centro Amazónico de Antropología y Aplicación Práctica (CAAAP) planteó la necesidad de llevar a cabo investi-

2 Debemos reconocer aquí la decisiva acogida de las autoridades universitarias de entonces en la introducción de la visión semiótica tanto en lingüística del discurso como en el análisis de textos literarios: Alberto Escobar, vicerrector de la Universidad Nacional Mayor de San Marcos y Luis Jaime Cisneros, Decano de la Facultad de Humanidades de la Pontificia Universidad Católica del Perú. Gracias a su apoyo, fue posible programar bajo los rótulos tradicionales de los cursos a mi cargo, por ejemplo, «Interpretación de textos literarios» (Curso n.․ 28-1775 de la Universidad Nacional Mayor de San Marcos, cf. Catalogo de cursos, junio de 1971-febrero de 1972, Lima, 1972, p. 428), un contenido estrictamente semiótico y verter en el dictado de dichos cursos la experiencia adquirida durante mis estudios de post-grado entre 1966 y 1969 en la École Pratique des Hâutes Études de París - VI ${ }^{2}$ me. Section. Dichos estudios realizados bajo la dirección de los profesores Jean Cassou, Roland Barthes, Algirdas Julien Greimas y Lucien Goldmann culminaron con la tesis titulada «Idéologie, critique et création chez César Vallejo», el grado Diplômé de la EPHE y la admisión en el Doctorado.

3 Luis Alberto Sánchez y Antonio Cornejo Polar fueron los institucionalizadores académicos de la literatura peruana: el primero, al haber aplicado los procedimientos taineanos a la producción literaria elitista y autorial y el segundo, al autoerigirse en mentor de la llamada crítica aerógrafa (su principio es «escribir en el aire») y heterogénea.

4 A. Cornejo Polar (cf. Varios, 1981: 46) escribía, por ejemplo, respecto del uso del metalenguaje semiótico en la descripción y control del análisis textual, que «la metodología se emplea tan vistosamente que finalmente no se sabe de qué se está hablando».

5 Para entonces ya había obtenido el doctorado en literatura de la Universidad Nacional Mayor de San Marcos al haber sustentado en 1971 la tesis Vallejo como paradigma (un caso especial de escritura) y en 1973 el doctorado en estudios ibéricos (especialidad de semiolingüística) de la Universidad de Paris III (Sorbonne Nouvelle) y de la École Pratique des Hâutes Études de París con la tesis La poétique de César Vallejo. 
gaciones y trabajos de campo etnosemióticos. Este último proyecto, cuyos resultados y publicaciones serán expuestos más adelante, constituyó una labor interdisciplinaria ejemplar que perduró varios años.

Como resultado de nuestra tarea inicial, se fundó en la institución universitaria peruana el espacio intelectual de base para el desarrollo pedagógico del conocimiento semiótico. El efecto fue inmediato: un buen número de estudiantes decidió sustentar sus tesis de grado aplicando, en la medida de sus posibilidades, los paradigmas semióticos de L. Hjelmslev, R. Barthes, A. J. Greimas y U. Eco entonces en boga y algunos de ellos (G. Dañino, $H$. Campodónico, R. Carrión), una vez graduados, decidieron proseguir sus estudios de especialización en el seno del Groupe de Recherches Sémioliguistiques, dirigido por el profesor Greimas en la École des Hâutes Études en Sciences Sociales de París 6.

De esta manera, en el mes de mayo de 1975 y bajo el auspicio personal de A. J. Greimas, se fundó en París la Asociación Peruana de Semiótica (APS) adscrita a la International Association for Semiotic Studies (IASS). Gracias al hecho de que sus miembros fundadores habían completado sus estudios de posgrado en ambos centros de instrucción parisinos y obtuvieron los respectivos grados y títulos de especialización semiótica, la Asociación centralizó y proyectó desde entonces el marco de las investigaciones semióticas peruanas, haciendo hincapié en la necesidad de idear, a partir de las teorías y modelos estándares, aproximaciones adecuadas a los fenómenos semioculturales propios de dicha sociedad.

En colaboración con la recientemente fundada Asociación Peruana de Semiótica (APS), se inauguró en 1976 el Centro de Investigación en Informática Aplicada a las Ciencias Humanas y Sociales (CIIACHS) de la Universidad Nacional Mayor de San Marcos. Entre otras áreas de actividad, dicho Centro comprendió una de Análisis Formales y Métodos Semiolingüísticos con tres secciones: Semiótica Jurídica, Análisis Semióticos de la Lengua Natural y Análisis Semioliterarios, y al firmarse el Programa de Cooperación Científico-Técnica con la Universidad de Carabobo en Valencia (Venezuela) se añadió la Unidad de Semiótica Jurídica.

Finalmente, los miembros de la APS ampliaron su labor de difusión semiótica por medio de cursos semestrales o anuales, cursillos, conferencias, asistencia a congresos, etc. en Venezuela (Universidad de Caracas, Instituto Rómulo Gallegos y Universidad de los Andes), la República Popular China (Departamentos de Lenguas Extranjeras de las Universidades de Beijing y

6 D. Blanco y R. Bueno se unieron a ellos, en calidad de oyentes, en el seminario del profesor Greimas durante un ciclo. 
Nanjing), México (Universidad Nacional Autónoma de México, Universidad Autónoma de Puebla) ${ }^{7}$, Estados Unidos (Arizona State University) y la llamada École de París con la cual mantienen estrecho contacto y colaboración académica hasta la actualidad.

\section{CAMPOS Y PRÁCTICAS SEMIÓTICAS}

\subsection{Teoría y metodología en semiótica general}

Además de la reflexión teórica y metodológica general de orden semiótico, el estudio de los objetos de conocimiento, constituidos a partir de la observación de la producción cultural peruana, comprende las siguientes áreas principales: literatura, poética, etnoliteratura, semántica, comunicación de masas y derecho. Veamos en seguida cada uno de estos aspectos.

A invitación del profesor lituano, E. Ballón Aguirre planteó en 19778 algunos principios epistemológicos para organizar la producción de discursos literarios en sociedades multilinguies y pluriculturales como la sociedad andina. Se propuso así un esquema general de la producción, circulación y consumo literarios capaz de integrar la etnoliteratura y de literatura escrita institucionalizada de la región y, a partir de esa organización, se trató de obtener una concepción del objeto de conocimiento literario distanciada de los criterios logocentristas que hasta entonces, y aún ahora, la dominan. Ahondando en esta misma vía, una de las preocupaciones constantes de ciertas investigaciones semióticas peruanas ha tenido como propósito constituir un criterio homogéneo de análisis para abordar el estudio de los textos de literatura oral diglósica (Ballón Aguirre-Campodónico, 1976a) y los textos monolingües sujetos a traducción. En este último caso, se hizo imprescindible elaborar una amplia exposición teórico-metodológica sobre los modos de producción de la literatura oral en sociedades multilingües y pluriculturales, proyecto que conjugó las perspectivas semiótica, sociolingüística y socioliteraria aplicada al problema específico del multilingüismo y la pluricultura peruanos (Ballón Aguirre, 1978b). En este sentido, se propuso un modelo regulador del corpus de variantes y sus manifestaciones textuales por medio de secuencias limitadas, gracias a demarcadores combinados en los planos de manifestación y contenido. Se estudiaron también los problemas de registro

7 Dicté los primeros cursos de etnosemiótica entre 1982 y 1985 en el Centro de Ciencias del Lenguaje de la Universidad Autónoma de Puebla y en la Facultad de Filosofía y Letras de la Universidad Nacional Autónoma de México, habiendo asesorado en 1984 al Dr. José Pascual Buxó y su equipo en la fundación de la Asociación Mexicana de Semiótica.

8 Cf. H. G. Ruprecht (1978). 
de la información proporcionada por los narradores y las coerciones de esta práctica. Todo ello fue puesto al servicio del análisis interdisciplinario semiótico y antropológico del mito de «Núnkui» perteneciente al grupo étnico aguaruna (jíbaro) del Perú (Ballón Aguirre-García Rendueles, 1978c).

H. Campodónico $(1978,1980)$ planteó, por su parte, un método operatorio para la definición de los lexemas idiolectales con miras a la organización de un corpus lexical semánticamente dependiente de la semiótica del mundo natural: por ejemplo, el léxico utilizado por los campesinos al distinguir las diferentes variedades de «tierras»; y en cuanto a la literatura oral, por medio de una ejemplar y extensa tesis ha logrado perfeccionar los procedimientos semióticos tradicionales europeos para evaluar sistemáticamente las transformaciones en un conjunto de variantes narrativas registradas por narradores pertenecientes a una determinada área sociocultural andina.

Por la misma época, J. L. Rivarola (1978a) planteó una posición normativa respecto de la descripción semántica de una lengua al sostener que «los semas, por ejemplo, son componentes de identidad precaria mientras no se haya practicado un análisis completo del inventario de sememas de la lengua en cuestión» ${ }^{9}$. En otro trabajo sobre historia de la lengua Rivarola (1978b) postula que «las lenguas no literarias pueden desarrollarse, pueden ampliar el radio de sus funciones, "progresar" en el sentido de ir copando nuevas esferas de expresión de la vida social y cultural y convertirse así en lenguas literarias», comprometiendo más directamente «el caso del quechua, respecto del cual una adecuación política y planteamiento lingüísticos pueden convertirlo en lengua literaria».

Si bien el manual publicado por S. Reisz (1986) sobre teoría literaria desarrolló sus fundamentos desde una perspectiva filológica y estética (dependiente de cierta visión globalizadora que comprendió la teoría de la recepción, de los géneros y de la discursividad), tocó problemas que competen directamente al área semiótica, por ejemplo, la organización modal, la tipología de los discursos, la enunciación, etc. Consecuentemente no encontramos aquí una especulación semiótica unitaria, sino más bien fragmentada, a lo cual contribuyó sin duda la diversidad de los paradigmas concurrentes (Genette, van Dijk, Jakobson, Lotman, Stierle...). Esta diversificación se vio superada cuando J. L. Rivarola y S. Reisz (1984) estudiaron la problemática del discurso referido a partir de la propuesta de M. Ron y el «indirect discourse, mimetic to some degree» de McHale para resolver algunos escollos

9 Esta hipótesis no tuvo en cuenta, en ese entonces, el hecho de que la descripción de los sememas depende del corpus textual elegido; que en cualquier discurso los semas no sólo son específicos e inherentes, sino genéricos y aferentes, debido a la participación de las coerciones semánticas provenientes del sistema, de la normativización sociolectal y del idiolecto. 
de la comunicación y producción discursiva. Los autores abordaron estos problemas a partir del proceso que ellos llamaron «conjunciones discursivas», es decir, la «presencia simultánea de dos actos de enunciación» en los discursos literarios y revisaron los conceptos de discurso directo, indirecto e indirecto libre con abundantes ejemplos tomados de la literatura latinoamericana e hicieron particular mención de los casos en los cuales un discurso se refiere en forma indirecta a la transportación deíctica, pero no a la construcción sintáctica propia del discurso indirecto (verbum dicendi y subordinación conjuncional) o del discurso indirecto libre (ausencia de verbum dicendi y de conjunción subordinante). En concurrencia, R. Bueno (1985a,b, 1988a) estudió por esos años los problemas teóricos de la semiótica literaria académica y la crítica literaria latinoamericana bajo ciertos postulados sociosemióticos, en especial los componentes narrativos mediante formalizaciones que vinculan tres factores del relato en un solo objeto teórico: autor implícito (hablante básico), voz (narrador) y tiempo de lo relatado.

Los problemas teóricos de una semiótica jurídica han sido abordados por R. Carrión (1977) a partir de una hipótesis múltiple sobre lo que él denominó pragmática jurídica e incluyó el «análisis del proceso de producción del discurso jurídico (considerando el fenómeno jurídico en su manifestación linguiística), los problemas clásicos sobre el legislador, el juez, el lenguaje jurídico, etc., se revelan coherentes y salen a la luz, por así decirlo, en un mismo nivel de funcionamiento efectivo de la comunicación jurídica». Los procedimientos metodológicos dependerían, entonces, de una semiótica jurídica lingüística en la cual «a) el objeto de estudio es el signo jurídico lingüístico concebido desde una teoría del discurso y b) este signo jurídico como discurso, es analizado en un primer momento en su proceso de producción específico, comprendiendo su funcionamiento social (comunicación) en la constitución del sentido» y como el lenguaje jurídico «es el portador del sentido y constructor de la significación social de lo jurídico», la descripción semiótica «intenta precisar con rigor científico, la constitución de la significación del universo lingüístico y semántico del discurso jurídico».

La difusión del método semiótico entre los no iniciados fue el propósito declarado del manual de D. Blanco y R. Bueno (1980). En efecto, allí se trató de hacer asequible al lector interesado el metalenguaje y los conceptos operatorios del paradigma de A. J. Greimas por medio de ejemplos simples tomados de la producción discursiva de la sociedad peruana, desde un relato oral hasta un cartel publicitario. No obstante el restringido espacio dedicado a la fundamentación teórica de dicho modelo, en ese manual se distinguen algunas funciones actanciales particulares del relato a partir de la iconicidad de los actantes en el plano de la manifestación textual e igualmente se precisan algunas articulaciones en el plano sémico, postulándose a la vez ciertos 
modos de articulación entre la estructura de superficie y la estructura profunda 10 .

Dos orientaciones complementarias distinguieron, en suma, este quehacer semiótico inicial: mientras unos investigadores reflexionaron sobre la teoría semiótica a partir de objetos singulares de conocimiento cuyo punto de partida fue la sociedad peruana, otros prefirieron bases más amplias que comprendiesen aquellos temas comunes a la especulación semiótica general. De esta manera se trató de lograr una concepción relativamente integrada al participar, por un lado, de las inquietudes generales del conocimiento semiótico y, por otro, de profundizar en los objetos de conocimiento semiótico propios de dicha sociedad. Todo ello motivó a P. Stökinger (1980) en su tesis de doctorado a dedicar una atención particular a los esfuerzos iniciales de la semiótica peruana en la cantera de la comunidad semiótica internacional.

A mediados de la década de los 80, D. Blanco (1985) planteó algunas hipótesis que permitiesen comprender y describir el encuadre de la semiótica general. Dichas hipótesis fueron ampliadas por Blanco (1989) al estudiar los discursos puestos en perspectiva comunicativa. Este punto de vista supuso concebir la significación como un producto de la experiencia social del grupo, es decir, la evaluación de la significación socialmente pertinente, en especial las condiciones de producción del plano figurativo del discurso. En un esfuerzo de orden epistemológico y sin abandonar los criterios de regulación analítica original, Blanco trató finalmente en esta obra de extender el modelo de la Escuela de París al indagar sobre los aportes de otras posturas semióticas relativamente congruentes.

Un nuevo campo de investigación teórico-metodológica, iniciado en las décadas de los 80 y 90 , fue el relativo a la situación multinacional, multilinguie y pluricultural de la sociedad peruana. A la noción de diglosia, tanto lingüística como literaria, E. Ballón Aguirre (1983b, 1986d, 1987f, 1989b, 1990b, 1999a, 2001b) sumó la de heteroglosia linguo-literaria para describir y analizar el fenómeno propio del contacto de las lenguas peruanas, sus interferencias y conflictos. En este área, ampliando las propuestas de la sociolingüística catalana, se observaron los valores semánticos e ideológicos que se

10 La crítica literaria tradicional, a través de uno de sus voceros (R. González Vigil, «En tomo al análisis semiótico». El Comercio, sup. Dominical, 25 de enero de 1981), no tardó en acusar al manual de Blanco y Bueno de «reductor» nada menos que por atenerse a un paradigma único que, sin duda, preservaba el rigor y coherencia necesarios en la demostración analítica; González Vigil agregó que «incluso si aceptamos estas reducciones, no entenderíamos la omisión de referencias a Barthes, Genette, Todorov, etc. en muchos aspectos necesarias para enriquecer o complementar el modelo greimasiano». La crítica literaria dejaba así traslucir los comentarios que echan mano de cuanto se les ocurre (lo mismo da Chana que Juana) para construir su propio «saber». 
producen en los discursos surgidos de esa situación socio-semiótica peruana en relación a la legislación sobre las lenguas, la política educativa del Estado y la comunicación de masas. En estos ensayos mereció atención especial el diagrama general de la situación linguo-cultural y literaria peruana, a partir del examen de las formaciones discursivas que se encuentran en las intersecciones endo- y exogrupales. Allí se propuso un modelo de base susceptible de describir, interpretar y explicar la producción literaria y la evolución de los objetos de conocimiento diglósico-literario de esa compleja sociedad, propuesta semiótica extendida en los últimos años por J. C. Godenzzi (1995) al tratar los documentos políticos del siglo XVIII en los Andes.

La investigación lexicográfica nacional de los años recientes se inscribió en ese mismo contexto ${ }^{11}$. Ante los conocidos defectos en que incurren los lexicones dedicados a las lenguas ancestrales peruanas, un grupo de investigadores ${ }^{12}$ decidió aplicar los criterios de la semántica componencial e interpretativa contextualizada por la semiótica a fin de resolver los nudos gordianos de la descripción léxica de dichas lenguas en un conjunto heteroglósico. Tomando como objeto de análisis la dimensión agronomía andina constituida en los discursos de la triglosia quechumara (quechua, aimara y español andino), se describieron desde el punto de vista onomasiológico las coerciones semánticas de dicho sociolecto, producto de la rica experiencia ancestral de la cultura andina. Ello permitió controlar, con la suficiencia requerida, el sistema de definiciones de la terminología obtenida mediante un trabajo de campo realizado con las mayores precauciones en este género de investigación. Luego - y ya en la perspectiva onomasiológica-, las microestructuras definicionales fueron establecidas no con equivalencias de traducción simple, frente a la lengua castellana andina predominante, sino directamente desde la ahormación semántica quechua. Este trabajo pionero instauró por primera vez el estudio disciplinado de la producción léxica de la sociedad peruana.

En el segundo lustro de la década de los 90, E. Ballón Aguirre y R. Cerrón Palomino ${ }^{13}$ estudiaron alrededor de 500 términos quechumaras empleados por la sociedad andina para denominar las variedades de papa producidas por ella. A partir de una revisión documental de la evolución de esas designaciones y del examen preciso de las acepciones que se les ha otorgado, en este extenso trabajo lexicológico y lexicográfico se aprovecharon los aportes descriptivos de las unidades mínimas de la significación para la organización y

11 Véase E. Ballón Aguirre (1985c).

12 E. Ballón Aguirre, R. Cerrón-Palomino y E. Chambi Apaza (1992).

13 Véase (en prensa) Terminología agraria andina (Nombres quechumaras de la papa). Cuzco: International Potato Center - Centro de Estudios Regionales Andinos «Bartolomé de las Casas». 
clasificación de los sememas (taxemas, campos, dominios y dimensiones) avanzados por la semiótica y la semántica interpretativa. A través del léxico se entrevé así la magnitud del saber agrario tradicional andino y se explican sus modos de adaptación a los cambios sociohistóricos sufridos en esa vasta región sudamericana.

En otra área de investigación aledaña se ha puesto atención especial a la teoría semiótico-antropológica sobre las «mesas rituales» y a la correlación de la literatura ancestral peruana con la producida en otras áreas geográficas. Dos estudios sobre los rituales andino y costeño dieron cuenta de estas manifestaciones de cultura tradicional. G. Martínez (1987) estudió la «mesa ritual» en los planos de expresión y contenido, así como el nivel narrativo de ese ritual compuesto por tres etapas: la construcción, la quema y la recepción de la «mesa». Al tratar de explicar la naturaleza semiótica de ese ritual, Martínez se aplica al esbozo de la estructura elemental y la modalización veridictoria susceptibles de formalizarlo. H. Campodónico (1985) amplía y al mismo tiempo puntualiza sus trabajos precedentes sobre las etnotaxonomías «referidas a la pregnancia semántica ligada a la categorización (lexical y semántica) del mundo», añadiendo los valores posicionales y de junción a la descripción de la «rigurosa tipología de la "mesa" del hechicero». Desde la perspectiva teórica estricta, Campodónico propone «reificar la paradigmática implícita en los discursos descriptivos y definicionales del campesino y construir una semiótica sincrética que reúna la semiótica natural con la socio(antropo- o etno-) semiótica». Ambos trabajos fueron complementarios en la medida en que emplearon una misma metodología (la semiótica de la Escuela de París) y, al perseguir fines similares, fundaron esta nueva área de conocimientos semióticos referida a la cultura popular.

En cuanto a la extensión de las investigaciones de E. Morote Best sobre la literatura oral peruana, E. Ballón Aguirre (1995c,d) propuso su renovación a partir de los motivos sintagmáticos que se encuentran en dicha literatura y en otras de distintas regiones, lo cual incentivó un amplio debate sobre los alcances semióticos en la descripción de objetos de conocimientos tradicionalmente asignados a la antropología 14 .

Para finalizar este apartado, señalaremos algunos temas puntuales dentro de la teoría semiótica, por ejemplo, la constitución del corpus. En un extenso artículo, dedicado a las confluencias entre la filología, la lingüística y la semiótica, E. Ballón Aguirre (1987e) consideró «un nivel de aprehensión cognoscitiva» en la constitución del corpus susceptible de garantizar los resultados del análisis etnosemiótico y permitir la formulación de nuevas

14 Intervinieron en dicho debate los semióticos peruanos M. N. Cuculiza (1995), F. Salazar Bustamante (1995) y C. Zanelli (1995). 
hipótesis de investigación. Para lograr establecer un corpus adecuado se precisó de varios registros cognoscitivos como los siguientes:

a) el procedimiento, la descripción y la construcción;

b) el modelo, la generación y la textualización;

c) la homogeneidad, la representatividad y la exhaustividad.

Estos parámetros tendieron a asegurar la validez disciplinaria del corpus y de este modo a propiciar una coherencia analítica desde una base textual coherente. Otro planteamiento teórico relativamente puntual tratado por Ballón Aguirre (1983a, 1985b, 1986c, 1986j, 1994c) fue el dedicado a un tipo especial de modalidades discursivas, las modalidades sustantivas como una clase especial de las modalidades halotácticas y traslativas. Se aprovechó el carácter discriminador de estas categorías verbales propias de la lengua española (doblemente manifestadas en relación, por ejemplo, a las de la lengua francesa) para precisar las propiedades «esenciales» (/ser/) y «existenciales» (/estar/) de la competencia de los actantes informada por esas modalidades.

\subsection{Análisis semióticos particulares}

\subsubsection{Cultura}

Como es bien conocido el principio de referencia común de las ciencias sociales en la definición de cultura durante la segunda mitad del siglo XX fue la antropología. Sin embargo, G. Dañino (1980) prefirió circunscribir el estudio de la semiótica de la cultura dentro del marco semántico de los valores de cultura a partir de la oposición categorial cultura / incultura en cada sociedad ${ }^{15}$. Esta relatividad del concepto operatorio de cultura obligaba a considerar tales valores dentro de cada «universo cerrado, suficiente, autónomo, coherente y sistematizado, apoyado en leyes funcionales que se convierten en signos y sistemas de comunicación, los cuales garantizan la transmisión de informaciones». Es en este sentido en el que la semiótica o «método de análisis de las formas de comunicación» podía abordar los fenómenos de cultura; pero además, a pesar de limitar la labor semiótica a ese único plano instrumental, G. Dañino incluyó una segunda oposición ahora de orden antropológico, natura / cultura, que al complementar a la primera facilitó el acceso a la «realidad cultural» de modo global. La semiótica de la cultura propuesta por Dañino comprendió, así, tres niveles de conocimiento: el de la

15 El presupuesto de esta categorización tiene en cuenta los únicos cuatro universales semánticos obrantes en todas las sociedades: vida / muerte y naturaleza / cultura. 
expresión (I), el de los textos (II) y el del contenido (III), cuyos componentes se esquematizan de la siguiente manera:

I. Lenguajes: sistemas de comunicación

Códigos: I II II

Media: oral/gestual escrito artístico-técnico

II. Espectáculos: secuencias de figuras simbólicas

Mitos: proverbios, relatos, historia, poesía

Ritos: gestos, modales, ceremonias, teatro

III. Ideología: lógica de los valores internos

Conocimiento: lo que se puedeldebe saber (ciencia)

Práctica: lo que se puedeldebe hacer (ética).

De modo más específico, E. Ballón Aguirre (1978b) planteó la urgencia de describir las restricciones de la producción pluricultural peruana. En el caso de la etnoliteratura, por ejemplo, habrán de preservarse y transcribirse ante todo las particularidades fonético-fonológicas de las declaraciones de los informantes, a fin de constituir un corpus correcto de variantes. Con igual propósito se defendió el hecho de que sólo la comprensión integral de los fenómenos de heteroglosia literaria oral y escrita permitirá un acercamiento desprejuiciado a los discursos producidos en dicha sociedad. La coparticipación de varios sistemas de valores culturales no llegó a producir aquí «discursos literarios híbridos», como todavía sostiene la crítica aerógrafa y heterogénea nacional, sino discursos distintos (diferentes y discretos) que solicitan un modo de comprensión no analógico-intuitivo sino hipotéticodeductivo en relación a los discursos literarios producidos por las formaciones sociales en que prevalece la monocultura. En cuanto a los objetos de cultura predominantes e institucionalizados como cultura oficial, por ejemplo, la literatura escrita de orden académico, el discurso icónico de la historia, la crítica literaria, etc. son emplazados en el campo de la sociosemiótica mientras que los objetos de cultura dominados como el folclore o la literatura oral ancestral y popular son asumidos por la etnosemiótica. Ambas semióticas son dependientes y tributarias de una semiocultura general que determina sus ámbitos de ejercicio profesional.

Los estudios semióticos sobre cultura de los lustros recientes se orientan a dilucidar la significación de los objetos pluriculturales producidos por la sociedad peruana, comenzando por la discusión referente a los rasgos defini- 
dores de los objetos institucionalizados por la cultura oficial (estudiados por la sociosemiótica) y sus opuestos, los objetos producidos por la llamada infracultura nacional (motivo de la etnosemiótica). En este orden de cosas, E. Ballón Aguirre (1983b, 1986d, 1987f, 1989b, 1990b, 1999a, 2001b) discutió el ordenamiento constitucional que jerarquizaba las lenguas peruanas en tres niveles: la lengua oficial española, las lenguas de «uso oficial» y las lenguas «nacionales», demostrando así el criterio etnocentrista y glotófago de la política linguiística del Estado peruano. Se destacaron en estos trabajos los efectos que la discriminación cultural trae consigo para la supervivencia de los valores originales de las lenguas ancestrales peruanas y, en particular, las imposiciones legales de los gobiernos incapaces de idear una política lingüística y cultural desalienada, por ejemplo, en la legislación educativa y sus efectos para la socialización de la cultura sobre todo en el léxico, los discursos literarios y los procesos de desemantización y resemantización que los aqueja.

En este campo la mayoría de los semióticos peruanos se inclinaron por investigar los productos de la cultura popular - como lo hizo T. Silva (1972) - ya sea en sus aspectos ancestrales, por ejemplo, los estudios dedicados a las crónicas peruanas de los siglos XVI y XVII por A. G. Fuentes (1988), R. Quispe $(1984,1987)$ y C. Zanelli $(1989,1992,1996,1999$ a, 1999b), los análisis de etnoliteratura tradicional realizados por M. Jara (1988) y C. Rubina $(1989,1990,1992,1995,1999)$, las aproximacions a ciertos rituales costumbristas o de comunicación de masas que hoy interesan a un buen sector de la docencia universitaria, por ejemplo, R. Bendezú (1985a, b, 1987, 1999), R. León (1973) u O. Quesada (1979, 1980, 1981, $1983,1986,1988$ b, 1999b). Esta proclividad por describir los valores culturales marginados se explica merced al interés de la semiótica, como ejercicio de denuncia y reivindicación, en desenmascarar los valores que según los sectores académicos oficiales identifican a la sociedad peruana.

\subsubsection{Cine y fotografía}

Las visitas y permanencias de Ch. Metz en el Perú han contribuido decididamente a afirmar el interés por el estudio semiótico del cine. De ahí que siempre, a partir de la semiótica de la Escuela de París, D. Blanco haya introducido en la crítica cinematográfica algunos dispositivos de descripción como el modelo actancial, los programas narrativos, las figuras del discurso, etc.

La estrategia analítica de Blanco (1974a, 1947b, 1976), aplicada a las películas de Bergman y Buñuel, incluyó también el modelo de M. Pechêux para explicar las condiciones de producción discursiva del proceso cinematográfico. Sin embargo, al examinar las «marcas» discursivas de las condiciones de 
producción y la presencia del «interdiscurso» en el texto fílmico, Blanco advirtió que esas condiciones sólo pueden ser conocidas a partir de las operaciones discursivas e identificadas desde la comprensión previa de las estructuras de significación, según el modelo desarrollado por A. J. Greimas ${ }^{16}$. Desde este punto de vista, los pasos a seguir en el análisis fílmico serían los siguientes:

I. Descripción de la estructrura de sentido a nivel superficial y profundo.

II. Identificación de las operaciones de producción según los paradigmas utilizados para el estudio de los distintos niveles y códigos.

III. Análisis de las condiciones de producción que han determinado la presencia de las operaciones discursivas contenidas en el filme estudiado.

IV. Descripción de los valores ideológicos implícitos y las condiciones de producción del sentido.

Destaca en este recuento la antología de comentarios realizados por D. Blanco (1987) entre 1965 y 1977 sobre una gama muy amplia de películas. Nos interesa destacar sobre todo aquellos artículos aparecidos entre 1972 y 1977 agrupados en dos capítulos titulados La estructura del filme y La ideología cinematográfica. No obstante el carácter periodístico de estos textos se tocan temas de semiótica general, por ejemplo, al afirmarse que «el sentido es resultado de una construcción» o que la crítica cinematográfica tiene interés «por perseguir los elementos de la estructura del filme y por esclarecer las relaciones que se establecen entre dichos elementos». Según Blanco:

\begin{abstract}
Las operaciones de producción del sentido están determinadas por condiciones materiales de producción discursiva. La relación entre aquellas operaciones y estas condiciones produce la ideología del discurso cinematográfico. La ideología entendida aquí como una gramática de producción; como un conjunto de reglas para construir un discurso y los efectos de sentido que él promueve.
\end{abstract}

El último enfoque de Blanco varía la línea de mira y nos dice que su crítica «se interesará por descubrir los mecanismos por los cuales el discurso habla

16 En desmedro de la coherencia noseológica del paradigma adoptado por Blanco, para la descripción de los otros aspectos del fenómeno fílmico él mismo propone aplicar los modelos de J. Kristeva, J. F. Lyotard, E. Verón, B. Pottier e incluso los aportes de la semiótica psicoanalítica. 
y la dimensión ideológica que construyen en cada discurso, desmitificando la transparencia de las imágenes y superando la simple descripción de las estructuras de sentido» 17 . Al contrario, en un notable estudio posterior relativo a la enunciación cinematográfica, Blanco (1988) desarrolló un meditado examen de las figuras de la cámara (movimientos, figuras de la planificación, figuras de los ángulos de toma) y las figuras sintagmáticas (sintaxis actorial, espacial y temporal) para ocuparse luego de los problemas de iconización y expresión así como de las figuras enunciativas del relato. Por los principios operatorios del análisis y la exhaustiva demostración emprendida, este trabajo es un modelo de rigor conceptual para las investigaciones semióticas sobre la producción cinematográfica.

La presentación de tres exposiciones fotográficas motivó a $\mathrm{E}$. Ballón Aguirre (1988a) ${ }^{18}$ sendas conferencias sobre semiótica de la iconización fotográfica. En estas conferencias se estudió el proceso de desemantización de cada una de las técnicas fotográficas allí empleadas. La representación planaria (los formantes figurativos) fue organizada a partir de dos tipos de categorías, topológicas (rectilíneas y curvilíneas) y plásticas (eidéticas y cromáticas) y el texto significante según la oposición continuidad / discontinuidad. Los contrastes y las anáforas plásticos dirigieron la información semántica de estos códigos semi-simbólicos y un fenómeno especial, la propiedad que tienen ciertos significantes de contener significados contradictorios, fue obtenida mediante la descripción del sistema de valores culturales detectado a través de la identificación y la interpretación del icono fotográfico.

\subsubsection{Artes plásticas}

La semiótica planaria ha sido igualmente objeto de una reflexión detenida. G. Dañino (1976) trató de esclarecer la común confusión entre las significaciones del objeto pictórico y la traduccón verbal de lo allí representado, proponiendo discriminar y tratar ambas organizaciones sémicas de modo independiente. En su intento por aproximarse a las condiciones generales de la expresión pictórica, aisló las unidades mínimas de la imagen - a la que considera como texto-ocurrencia u objeto de conocimiento a ser descrito por el análisis semiótico- y anticipándose a los trabajos de J. M. Floch y F. Thürleman, G. Dañino propuso que la comunicación artística y

17 Sin embargo no encontramos en los textos antologados una sola «descripción de las estructuras del sentido» ni simple ni compleja a superar.

18 En la Galería de Arte de la Municipalidad de Miraflores, Lima, 1986-1987. Fotografías de Martín Chambi, Billy Hare y Javier Silva. 
las connotaciones culturales de la imagen pictórica eran el objeto de observación del conocimiento semiótico. A partir de este postulado se ocupó de las condiciones físicas o materiales de la producción de dicha imagen y describió su sistematización a partir de un primer nivel, los códigos de percepción óptica compuestos por optemas (luminosidad, precisión, cromaticidad, espacialidad, luminosidad) y semas (figuración, perspectiva, conjuntos sintagmáticos, composición). Otros dos niveles se añadieron al primero, pero ambos pertenecen al enunciado linguístico adosado a la imagen: el nivel metasemiótico pictórico o léxico conformado por las denominaciones de las unidades discretas encontradas por los códigos ópticos y el nivel metalingüístico que comprende las significaciones lingüísticas adheridas a la imagen, como el título o títulos, los cuadros en secuencia intertextual, las leyendas insertadas en la imagen, etc. Este trabajo pionero concluyó con una hipótesis sobre la construcción de la imagen significativa y algunas precisiones de orden metodológico.

Siempre dentro de este mismo tópico, la tesis sustentada por U. Ramírez (1972) fue dedicada a estudiar un texto de exégesis pictórica escrito por el gran poeta peruano César Vallejo. Este estudio se inspiró en los análisis icónicos de R. Barthes y describió en primer lugar los objetos plásticos comentados en la crónica de Vallejo a la vez que organizó, en segundo lugar, el plano de la significación de los enunciados textuales tomados como referentes de enjuiciamiento. Este análisis se ocupó principalmente de las isotopías allí codificadas con el fin de explicar la generación y transformación que sufren las significaciones al pasar de una a otra materia textual, es decir, el proceso de traducción —en sentido semiótico- de las manifestaciones semánticas reunidas por un sólo metadiscurso.

A pesar de la escasez de análisis semióticos de obras plásticas, podemos citar los estudios de O. Quezada (1980) y E. Ballón Aguirre (1987d) sobre los «estandartes» de P. Zignago ${ }^{19} \mathrm{y}$ los «lozenge» (cuadriláteros en punta) de P. Mondrian. En estos últimos casos la perspectiva del análisis fue tanto lexicográfica (la denominación de los objetos heteróclitos sometidos a la percepción) como sintagmática (la discursivización de un motivo pictórico en un texto estético y en un cuadro). El problema central es la correlación entre el objeto artístico y el discurso en lengua que permite aprehenderlo no como valor o juicio crítico sino como serie de enunciados descriptivos y explicativos. En efecto, la organización del sentido en lengua obedece a restricciones significativas de las unidades menores como los lexemas y, al mismo tiempo, de las unidades mayores como las secuencias. Al no abarcar dichas limita-

19 E. Ballón Aguirre, «Urdimbres y sobras», diario La República, Lima, 21 de junio de 1986, 21. 
ciones la captación del sentido cuando se percibe el objeto plástico, el comentario está condenado a reducir las propiedades significativas que ostenta ese objeto. Por lo tanto, en estos estudios de semiótica planaria no se trató de eliminar o sustituir esas limitaciones sino de controlarlas por medio de una regulación del léxico que describe el objeto pictórico y el discurso del mismo pintor que traslada las significaciones pictóricas de su tela a la escritura: en Mondrian, por ejemplo, ciertas pinturas son ilustraciones de sus propios textos de teoría y debate estético. Finalmente se trató de conciliar los programas de anaforización cognoscitiva que identifican el «arte naturalista» y los programas de categorización cognoscitiva que permiten la apreciación del «arte abstracto».

\subsubsection{Literatura}

\subsubsection{Poética}

S. Reisz (1977a) reservó el término «poético» para designar todo texto literario en verso u organizado según algún principio rítmico sonoro y/o visual de cuya aplicación resultase una segmentación de la cadena fónica y/o gráfica no coincidente con la usualmente practicada en el habla cotidiana. Si bien se aceptó en este proyecto de teoría semiótica literaria la presencia de al menos uno de los tipos de equivalencia propuestos por R. Jakobson, no se le consideró suficiente para definir la «poeticidad», es decir que la disposición poética de los enunciados - su alternancia regular con márgenes blancos o silencios que los aislan del universo de los textos pragmáticos- se erige en rasgo distintivo sólo en relación con un conjunto de códigos (de época, genéricos, literario-ficcionales, estilístico-temáticos, etc.) que se superponen al de la lengua y con las condiciones pragmáticas de su utilización. Los textos poéticos parecen caracterizarse, entonces, por una densidad y complejidad informativas de un grado más alto que los demás textos literarios, pues en ellos hay una mayor concentración de elementos no-precodificados en el sistema de la lengua, ellos mismos son portadores de informaciones parciales adicionales que trasladan las informaciones expresadas por los elementos precodificados. En el mismo estudio intervinieron algunas nociones del análisis de la recepción y, sobre todo, la tesis lotmaniana del carácter significativo de todas las equivalencias estructurales, todo ello aplicado a la obra poética de Catulo donde se describe tanto la variedad de efectos de sentido derivados de la recurrencia de unidades lingüísticas (de distintos niveles) como las relaciones de interdependencia entre los elementos equivalentes superpuestos en dichos niveles fonológico, prosódico, sintáctico, etc. y el nivel semántico. 
En otro trabajo del mismo año, S. Reisz (1977b) examinó el parentesco y los rasgos distintivos de dos fenómenos semióticos frecuentemente representados en los textos literarios en los que el sentido literal de un segmento textual (o de un texto completo) exige el tránsito a un sentido no-literal. Ahora son los modelos de metáfora según $\mathrm{K}$. Stierle y de símbolo según J. Link los que permiten elaborar un modelo contrastivo de ambos fenómenos para demostrar que la diferencia entre la «metáfora aislada» y la «metáfora continuada» o «alegoría», ambas marcadas por la oposición continuo / discontinuo, se funda en dos sistemas de relaciones distintos y no - como lo quiere la retórica - en la diferente extensión de las manifestaciones de un mismo sistema. Se incluyó aquí también una tipología del discurso simbólico ilustrada con extensos análisis de textos poéticos de diferentes épocas, rescatándose de paso el aporte del pensamiento clásico (Aristóteles y Quintiliano) en la fundamentación de ciertas categorías elaboradas por la teoría literaria de orientación semiótica.

Siguiendo esta misma línea de reflexión S. Reisz $(1979,1980$ b, 1981) expuso la relación entre la concepción artistotélica de la literatura y el arte en general como «mímesis» y la definición lotmaniana de los sistemas artísticos como modelizadores secundarios. Con la «mímesis» quedó implícitamente aludido el carácter modelizador de todas las artes y con el reconocimiento aristotélico de la existencia de un conjunto de normas que regulan la construcción del mundo ficcional en cada género literario y de un subcódigo lingüístico, igualmente propio de cada género, quedó abierto el camino para el reconocimiento de la literatura como sistema modalizador secundario y del texto literario como producto de una doble codificación, según el código de la lengua y según una jerarquía compleja de códigos artísticos variables para cada época, género, estilo, etc. Ahora bien, el hecho de que la lírica esté ausente en la clasificación platónico-aristotélica de los géneros literarios se debe a la acertada intuición de que la lírica se opone a la narrativa y al drama como estas dos formas se oponen entre sí, todo lo cual se relaciona con la concepción de $\mathrm{K}$. Stierle por la que la lírica es concebida en tanto transgresión de cualquier tipo de esquema discursivo y, en consecuencia, permite fundar los cimientos para una posible tipología de los discursos literarios.

En lo referente a la «ficcionalidad» se revisó la teoría de J. Searle y se propuso, en cambio, partir de la noción procedente de J. Landwehr de «modificación intencional de las modalidades atribuibles a los constituyentes de la situación comunicativa». Ello permitió a Reisz replantear, con ayuda de diferentes fundamentos epistemológicos, tanto el inventario de las modalidades como la relación entre la modificación de las zonas de referencia (la constitución del mundo representado en la ficción) y la 
modificación del rol de productor (la constitución de una fuente de lenguaje distinta del autor). En el mismo estudio y a partir de muestras tomadas de la literatura fantástica se discutió la tipología de las ficciones literarias, destacándose el papel de la «poética de la ficción» variable y del «verosímil» propio de cada género (Aristóteles) para concluir que la diferencia entre las ficciones literarias y las no literarias y, en general, de las ficciones vinculadas con los sistemas artísticos respecto de los no-artísticos, es que tanto su producción como su recepción están orientadas por una instancia normativa (por una «poética ficcional») variable para cada género y época.

El estudio semiótico de las crónicas periodísticas del gran poeta peruano César Vallejo apareció publicado en 1985. En tres volúmenes, en los que se incluyó un corpus de más de 250 crónicas, E. Ballón Aguirre (1984-1985, 1985a) analizó la evolución de los valores ideológicos del poeta a través de cuatro tópicos: la poética, la poemática, la política y el compromiso. No se trató aquí de fundar una poética, sino de examinar las coerciones semánticas propias de este tipo de discurso paraliterario y describir su programa productor de poetología. De acuerdo a los resultados del análisis tal programa dispone de dos dimensiones, cognoscitiva y deóntica, aplicadas a un discurso-objeto determinado -que puede incluir los discursos literarios del propio poetólogo-, a partir del cual se organizan otros discursos como el discurso socio-cultural, el discurso exegético y el discurso indeterminado sobre acontecimientos y estados de cultura o del mundo en general.

Los resultados teóricos y metodológicos obtenidos en este ensayo permiten asegurar un tratamiento coherente y riguroso de interpretación capaz de superar los tropiezos heurísticos y hermenéuticos de la filología y la crítica literaria corriente. Estas últimas especulaciones emplean, como se sabe, procedimientos inductivos que, por fuerza, producen un abanico de interpretaciones textuales incoherentes entre sí; la «polisemia» del texto poético sugiere múltiples «lecturas», sin que pueda establecerse un control demostrativo entre las diversas interpretaciones dadas. Al contrario de estos procedimientos descontrolados, en el estudio reseñado se tomó como punto de referencia los escritos paraliterarios de Vallejo —donde expone su poéticay así se contó con una referencia «legítima» de base. Analizando luego semióticamente el régimen de valores apreciativos y de evaluación (los juicios poéticos) allí enunciados, se estableció el régimen poético consciente del poeta en una doble orientación: hacia las obras literarias ajenas que somete a su enjuiciamiento y hacia los textos literarios de su propia mano. De este modo, se procuró superar el muy conocido descontrol interpretativo de los textos literarios por obra de las exégesis críticas peruanas ajenas al quehacer semiótico. 


\subsubsection{Análisis de textos}

El análisis de textos fue y es todavía la principal actividad semiótica en el Perú. En efecto, la pedagogía de la disciplina semiótica se encaminó a demostrar las ventajas de la teoría y metodología de esta rama del saber en la descripción y explicación de textos de literatura oral y escrita frente a los modos tradicionales del comentario crítico indisciplinado. Tal es la razón por la que un buen número de estudiantes optó por tomar como guía de sus investigaciones los modelos originales ideados por R. Barthes, A. J. Greimas o U. Eco. En este apartado tocaremos lo referente a la literatura escrita dejando para más adelante los trabajos sobre literatura oral andina y amazónica.

La primera tesis doctoral defendida en el Perú - y con ello también la primera investigación semiótica publicada- es la que sostuvo E. Ballón Aguirre (1974) en la Universidad Nacional Mayor de San Marcos de Lima en 1971. Reuniendo los criterios de explicación textual elaborados hasta entonces por sus profesores R. Barthes y A. J. Greimas, utilizó los primeros para describir la producción intertextual del poema de César Vallejo En el momento en que el tenista... (de Poemas en prosa) y los segundos para demostrar la generación de ese mismo texto poético. Se examinaron así, en vía genética, las transformaciones semánticas ocurridas entre los pre-textos y el texto definitivo, pasando por todas las etapas de escritura del poema: la redacción inicial de dos crónicas periodísticas, un texto en prosa y, por último, las diversas versiones del poema. Complementariamente y en vía generativa, se estudió la versión final de ese texto siguiendo el proceso deductivo que va de las unidades mínimas de la significación en la estructura profunda hasta su actualización en la estructura superficial donde se precisan las figuras. Una vez descrita la estructura figurativa se estudió la iconización que representan dichas figuras en la manifestación textual. Sin embargo la tesis no se limitó a aplicar la teoría y los métodos operatorios de la semiótica, ya que, una vez concluida la descripción analítica, se plantearon los criterios de interpretación que permiten definir el «corte epistemológico» producido por la escritura vallejiana en la evolución de la cultura peruana 20 .

Otros análisis de textos poéticos fueron sustentados por A. M. Rocha (1972) y G. Dañino (1972). El primero tuvo como objeto de conocimiento el poemario Cinco metros de poemas, de C. Oquendo de Amat, y el segundo el poemario Rondinelas, de J. M. Eguren. En ambos estudios se ensayó la aplicación del método greimasiano no ya a un sólo poema como en el caso ante-

20 K. A. McDuffie ha realizado una extensa evaluación de este trabajo en la reseña titulada «Vallejo como paradigma (un caso especial de escritura)», Revista Iberoamericana XL, 89 (1974), 719-723. 
rior, sino repertorios completos y, además, en la tesis de Rocha, a la distribución espacial de la escritura calligramática. Los contenidos ideológicos de la escritura versificada en algunas muestras del folclore peruano, fue el tema de la tesis de grado defendida ese mismo año por T. Silva (1972); posteriormente Silva, bajo la dirección del profesor B. Pottier de la Universidad de París, amplió y profundizó su trabajo inicial.

Mucho más numerosas fueron las disertaciones dedicadas a la narrativa literaria. Dos de ellas, las de R. M. de los Heros (1972 y 1975) y R. Arias (1972), se abocaron a estudiar los relatos de G. García Márquez poniendo especial atención a la organización de los programas narrativos y la literalidad de los contenidos. Luego las tesis de $\mathbf{L}$. Ruiz $(1972,1973)$ constituyeron una amplia exposición del análisis microestructural aplicado a un texto de $\mathrm{A}$. Bryce, mientras que E. Huarag (1974. a , 1974b) incidió en la determinación de los criterios pertinentes para lograr una aproximación semiótica al relato, a partir de las propiedades de la enunciación literaria. La demostración de estos postulados fue hecha sobre los textos del conocido escritor J. R. Ribeyro. R. Lerner (1987) estudió, por su parte, el discurso subjetivo de una novela del escritor Alfredo Bryce. Si bien el propósito de esta tesis no fue exclusivamente semiótico, en este caso se emplearon criterios análogos al tratar la intervención del enunciador en su propio texto.

Siempre dentro de los análisis de textos literarios, pero ahora relativos a los problemas de verosimilitud práctica y mítica en el relato, se encuentran los estudios de A. González (1972) sobre un cuento de E. López Albújar y C. Gutiérrez (1976) que explica los alcances de la articulación entre el verosímil histórico y el verosímil narrativo en una novela de F. Vegas Seminario. Con un proyecto de mayor aliento, A. M. Gazzolo (1974) escogió tratar de manera exhaustiva el sistema actancial actualizado en la estructura superficial de un gran texto diglósico literario, El zorro de arriba y el zorro de debajo, de J. M. Arguedas. Un nuevo estudio sobre este mismo texto fue emprendido por M. Juan Saura (1988), quien trató de determinar la organización de la espacialidad y sus efectos en el discurso. Gracias a estos y otros estudios semejantes, se comenzó a conocer la naturaleza propia de la literatura diglósica peruana (generalmente estudiada bajo los mismos criterios aplicados a la literatura académica) profundamente ligada a la problemática multilingüe y etnológica.

Cabe incluir en este apartado la presencia de otros análisis de textos, especialmente sobre los escritos por el poeta peruano C. Vallejo. E. Ballón Aguirre (1977a, 1977b y 1981) propuso reemplazar el discurso veleidoso de la crítica literaria por una metafrasis regulada, utilizando para los efectos de control intratextual la metodología semiótica. La coherencia simbólica del 
poema Trilce fue interpretada así a partir de su estructura narrativa y el examen de la isotopía temática de base, que en esta circunstancia es el espacio, requirió añadir dos posiciones espaciales no consideradas por el modelo canónico de la Escuela de París: los espacios «ectópico» y «atópico» aprovechados precisamente por la poesía lírica. Por último, al aplicarse el mecanismo de los conectores semánticos entre las isotopías noológica y cosmológica, se inauguró la aplicación de ese discriminador semántico en poesía.

En las décadas siguientes el mismo Ballón Aguirre (1981, 1982a, 1982b, 1988c, 1988d, 1989a, 1989c, 1994b) ha dedicado algunos ensayos semióticos tanto a la prosa de J. C. Mariátegui como a la poesía de Vallejo, el teatro y la correspondencia entre ambos escritores. El análisis exhaustivo de un relato de Mariátegui permitió entrever los valores ideológicos que precedieron inmediatamente a la opción marxista de este notable ideólogo y en los poemas vallejianos se observó tanto la constitución de la espacialidad lírica como la función simbolizadora del «yo» poético en los discursos poéticoegotistas, los acrósticos. Además, dentro de este mismo campo, se inició en el Perú el estudio semiótico de las piezas teatrales con el examen de las perculiaridades lingüísticas - especialmente léxicas-y las isotopías diglósica, social, política y estética de una compleja obra de teatro vallejiana, Colacho Hermanos o Presidentes de América.

Los grandes poemas epistolares o de correspondencia romanceada entre Sor Juana Inés de la Cruz y los poetas del barroco peruano en el siglo XVII, singularmente la poesía atribuida a Juan del Valle y Caviedes, fueron motivo de amplios análisis emprendidos por Ballón Aguirre (1996, 1998a, 1998d, 1998e, 1999d) durante la década de los noventa. Debido a su complejidad, esta cantera de investigación, actualmente en estudio, requiere de una aproximación interdisciplinaria tanto filológica como retórica y semiolingiuística a fin de obtener una interpretación correlacionadora de todos los niveles discursivos.

R. Bueno (1976) ${ }^{21}$ aprovechó de un estudio del poema Cazador de F. García Lorca para proponer una hipótesis sobre la función del «argumento» instituido en plano inteligible del texto poético y amplió el conocido postulado de R. Jakobson que caracterizó el modo de existencia del discurso poético desde la proyección del eje paradigmático sobre el eje sintagmático de la lengua. Posteriormente el motivo de la «seducción» en un texto poético de J. M. Eguren sirvió a D. Blanco y R. Bueno (1978) para ilustrar la des-

21 En la misma revista en que apareció el artículo de Bueno, se publicó el estudio de P. Froëhlicher, «Lectura de un poema de Apollinaire» (Letras, 84-85, 1976, 1ll-120). Es el texto de la conferencia leída por el autor, profesor de semiótica de la Universidad de Zurich, en el Programa de Literaturas Hispánicas de la U.N.M.S.M., el 21 de setiembre de 1976. 
composición de los distintos planos en que se puede describir el texto poético al aplicar el procedimiento previsto por F. Rastier. El fenómeno de la «pluralidad de lecturas» es también mencionado como un aspecto del acercamiento analítico 22 .

El enfoque semiótico en el abordaje de los textos poéticos de la vanguardia hispanoamericana fue aprovechado por R. Bueno (1979, 1981, 1986a, 1987) para explicar las asociaciones simbólicas características de ese movimiento literario. Los tópicos de la enunciación y de la intertextualidad poéticas permitieron constituir, en esos textos, la isotopía temática de base y las principales isotopías figurativas que la sostienen, todas extendidas por medio de los códigos a un corpus más amplio hasta llegar a determinar lo que podríamos concebir como un grupo de «isotopías obsesivas» en la obra borgiana. La lógica de las acciones y de las posiciones narrativas (tratadas, es cierto, de modo sui generis) revelaron la especificidad narrativa del escritor argentino. Pero la situación es distinta cuando se trató de la escritura poética de Neruda. En este último caso se destacó la diferencia sustancial entre la productividad estilística «cargada de intuicionismo y psicologismo» al ser aplicada a la interpretación textual y la productividad semiótica del conocimiento literario. En el plano metodológico se describió un nuevo proceso denominado «ósmosis semántica», mientras que el análisis poético descansó en la categoría sémica «temporalidad», lo cual justificó entonces el examen de las posiciones del enunciador en el plano ideológico y su transformación desde una visión individualista y abstracta del tiempo hasta su modificación por una concepción social y materialista. En tal sentido podemos afirmar que los tópicos de la espacialidad y la temporalidad en poesía, son un enclave semántico fundamental para la interpretación de los textos poéticos producidos por la sociedad peruana.

Bueno (1984a, 1985b, 1999) ahondó luego sus puntos de vista sobre la vanguardia latinoamericana y en varios trabajos dedicados a la obra de Vallejo, Cardenal, Borges, Neruda, Oquendo de Amat, etc. se afanó por dilucidar la «agramaticalidad» de esta escritura literaria. Una vez realizado el deslinde teórico sobre el lenguaje poético y la poesía en general (planos de manifestación y contenido, sintagmática e intertextualidad), los procedimientos semióticos empleados con ese fin tendieron a determinar las figuras y configuraciones discursivas de mayor recurrencia, construyendo con ellas

22 Advertiremos que el criterio de «pluralidad de lecturas» sale del marco de pertinencia cognoscitiva de la semiótica. Blanco y Bueno consideran que otros tipos de aproximación al texto constituyen la lectura plural, por ejemplo, los discursos críticos intuitivos y se admite la coparticipación de la crítica literaria creadora de valores a la par del análisis semiótico que por definición sólo describe valores: la lectura plural no es, en realidad, otra cosa que una simple lectura descontrolada. 
las relaciones sintagmáticas que tienen el propósito de perfilar la estructura de significación de cada texto. En los posteriores estudios dedicados a la poesía del científico brasileño Cardozo, del pensador characateño Guzmán y del comunicólogo mirafloreño Blanco, Bueno describe las configuraciones discursivas, los programas de uso y los problemas de la veridicción. Fuera de estos asuntos relativamente puntuales, Bueno (1985a, 1988a, 1986b, 1986c) ha comentado igualmente el quehacer crítico literario latinoamericano y ha delineado algunas pautas de orden socio-semiótico para correlacionar el discurso literario y los efectos de realidad que éste produce. En esta oportunidad se privilegió la producción literaria peruana en razón de la diversidad de formaciones discursivas surgidas del multilingüismo y la pluricultura vividos por esa sociedad.

En cuanto a la constituición del corpus, cabe anotar que tanto en los trabajos de Ballón Aguirre como en los de Bueno hay una preferencia declarada por la correlación de variantes intertextuales con la que se trata de plantear o reargüir las hipótesis en un marco textual lo suficientemente extenso como para establecer modelos fuertes de interpretación semiótica, modelos que luego posibiliten configurar una tipología de los discursos poéticos.

Durante los años setenta, el notable lingüista peruano A. Escobar (1974, 1981) comenzó también a interesarse en al análisis semiolingüístico del texto a fin de contar con un procedimiento heurístico que garantizase luego el enjuiciamiento crítico. En un extenso libro sobre la obra del escritor J. M. Arguedas, Escobar (1984) aprovechó numerosos aspectos del paradigma teórico-metodológico de A. J. Greimas para dilucidar, en primer lugar, las variaciones de las estructuras de significación en las distintas versiones de los relatos y en seguida para determinar las estructuras narrativas y discursivas generales de ese corpus relativamente vasto. El objetivo central del trabajo emprendido por Escobar fue describir, interpretar y explicar las características particulares que adquieren los discursos literarios de Arguedas como fruto del bilingüismo allí representado. Esta investigación, pionera en varios sentidos, destaca la rentabilidad de los procedimientos semióticos cuando se trata de conocer discursos altamente complejos desde el punto de vista de su ahormación semántica. Si tenemos en cuenta que la inmensa mayoría de discursos (no sólo literarios) producidos por la sociedad peruana se hallan inmersos en la diglosia quechumara, podemos inferir la importancia de la obra de Escobar para las investigaciones semióticas interesadas en conocer los fenómenos sociolectales de la sociedad andina definida por su heteroglosia integral.

Además de esta obra fundamental, A. Escobar (1988a, 1988b, 1989) aplicó la metodología semiótica al estudiar la poesía de C. Vallejo y otros 
poetas peruanos como E. A. Westphalen y C. Moro. El enfoque semiótico en este último caso tomó como punto de referencia algunas reflexiones analíticas de R. Barthes, especialmente aquellas dedicadas a la densidad denotativa y connotativa de las figuras, iconos, imágenes, blasones y emblemas poéticos. Desde allí Escobar trató de encontrar los modos comunes de «poetizar» propios de una generación de escritores, es decir, las pautas poéticas determinantes de una formación discursiva peruana poco conocida y peor interpretada. No obstante, no se limitó a observar el fenómeno textual en sí mismo. En efecto, una preocupación inmediata y común a estos análisis textuales es la correlación de los textos con los fenómenos linguoculturales en que tienen vigencia, por ejemplo, las distintas tradiciones literarias del español hablado en el Perú y su impronta en los poemas escritos originalmente en francés por E. A. Westphalen.

Como ya advirtiéramos y a pesar de la diversidad de los asuntos tratados, un conjunto coherente de análisis de textos tanto poéticos como de prosa es el constituido por los trabajos que en esta época emprendiera S. Reiz (1977a, 1977b, 1979, 1980a, 1980c). Nos cabe precisar en seguida que el ya mencionado estudio de la obra de Catulo se dividió en tres grandes rubros (repetición de lexías, paralelismos sintácticos y campos semánticos) y los análisis de los poemas fueron destinados a ilustrar de modo exhaustivo cada tipo de equivalencia entre los estratos textuales. Este procedimiento se reiteró al averiguar dos nociones-clave de la poética borgeana —l «postulado fantástico pero no sobrenatural» $y$ «obra de imaginación razonada»- en forma de reflexión metaliteraria que permite, como ocurre con el caso de C. Vallejo (Ballón Aguirre, 1979a), superar ampliamente los discursos de la crítica literaria en la materia. Finalmente, Reisz estudió la práctica renacentista de la imitatio en un análisis semiótico comparativo de un pasaje de la Égloga III de Garcilaso de la Vega y de su modelo latino, la Égloga VII de Virgilio. Se destacaron allí los sistemas culturales y las normas estéticas que se manifiestan en ambos textos y se confrontó el texto recreado con otras recreaciones y traducciones a que ha dado lugar el modelo, para concluir que es más propio hablar de un proceso de «transferencia» que de una «imitatio», esto es, el paso de un sistema poético a otro sistema poético cerrado e independiente, pero construido según las mismas reglas estructurales.

El arduo problema de la producción de la literatura escrita a partir de la literatura oral peruana fue, finalmente, un amplio tema de investigación y análisis textual tendente a fundar la comprensión de la producción literaria general en la sociedad peruana. Este proyecto abarcó la discusión sobre los llamados «orígenes folclóricos de la literatura» y la supervivencia de las «contra-literaturas» a través de una visión global semiótica y diglósica. Lo que se vislumbró en estos estudios (Ballón Aguirre y Cerrón-Palomino 1990, 
Ballón Aguirre 1999a, 2001b) es la descripción de las estructuras diglósicas o diglosia literaria propiamente dicha, el enfoque de la literatura peruana no a partir de la institucionalidad tributaria de la crítica literaria al uso, sino desde el sustrato lingüístico heteroglósico en el cual se origina toda la producción y generación de los discursos literarios peruanos.

\subsubsection{Literatura oral}

Bajo el enunciado «literatura oral» comprendemos tanto las investigaciones de literatura oral popular, en cuyos textos se combinan valores semánticos occidentales y etnoliterarios (leyendas, cuentos, tradiciones, comadreos, etc.), como las de literatura oral ancestral que contiene valores nativos relativamente independientes (mitos, poesía étnica, etc.).

El trabajo de mayor relieve en literatura oral peruana es la tesis que sostuviera H. Campodónico en la Universidad de París (Sorbona) en 1980 titulada Literatura oral del norte del Perú: aproximación semiótica. En ella se describe, analiza y explica un conjunto de 16 relatos de base y una addenda de 13 relatos con fines comparativos, todos narrados directamente por los campesinos de la costa norte del Perú (Chiclayo y sus alrededores). El antecedente inmediato de esta disertación fue una ponencia presentada en el XLII Congreso Internacional de Americanistas de París (Ballón Aguirre-Campodónico, 1976), en la cual el análisis se limitó a dos variantes textuales cuya hipótesis luego debería ser redarguida, cosa que precisamente se lleva a cabo en dicha disertación. Esta ponencia se limitó exclusivamente a desarrollar la estructura de superficie del relato oral, lo que no permitía ver en claro la estructura de lo verosímil, es decir, la necesidad de distinguir un verosímil mítico para el efecto de sentido producido por la isotopía noológica y la dimensión cognoscitiva y un verosímil práctico para el efecto de sentido correspondiente a la isotopía cosmológica y a la dimensión pragmática 23 .

En términos generales se procedió, en la disertación, a poner en práctica un estudio de las transformaciones intertextuales a la manera de C. LéviStrauss, lo cual facilitó una primera organización de dichos relatos según la homogeneidad o diferenciación del contenido. Luego se abordan las transformaciones semánticas según el modelo del recorrido generativo de la significación, lo que permitió organizar deductivamente el micro-universo de sentido en los planos profundo, superficial y discursivo. La comparación entre variantes fue efectuada por medio de las imbricaciones (overlapping)

23 En esta investigación inicial se aprovechó ampliamente el estudio de J. L. Rivarola y K. Baldinger (1974). 
entre las isotopías sintagmáticas, paradigmáticas, temáticas y figurativas encontradas en los relatos-tipo. Se destacaron, por último, las estructuras semántica y sintáctica de los valores lógico-semánticos, su incorporación en los ejes sintácticos (sintaxis actancial y modelo narrativo de superficie) y su correlación en discurso (procedimientos de actorialización y espacialización). Esta investigación central se completó con un estudio comparativo de otras variantes textuales de la narrativa oral hispanoamericana donde, por medio del análisis semiótico, se llegan a especificar los elementos singulares que definen la narratividad y los motivos informadores del corpus establecido.

En cuanto a los aspectos periféricos, el apartado introductorio de la disertación contiene una breve referencia geográfica e histórica sobre la lengua y la cultura de la zona investigada. Se presenta también a los informantes narradores, la isotopía temática general en torno a la figura de un árbol, el «higuerón», sus vinculaciones con las isotopías noológica y cosmológica obtenidas de la formación socio-cultural campesina de dicha zona y las referencias bibliográficas del tema. En lo referente al núcleo demostrativo, éste se divide en dos grandes partes: los preliminares al análisis semiótico de los textos y el análisis respectivo. En los preliminares -que comprenden cuatro capítulos- se explica el estatuto semiótico del corpus, los límites del estudio, el programa de investigación, las hipótesis de trabajo, las definiciones operatorias o criterios epistemológicos empleados, los conceptos no definidos pero considerados axiomáticamente aceptables $\mathrm{y}$, por último, los criterios descriptivos según el recorrido generativo del discurso. Se agrega también una breve reseña de las características del sociolecto campesino en los relatos orales y en cuanto a la determinación del conjunto textual, una explicación detallada del método de encuestra, el registro y la transcripción fonológica. Un capítulo distinto está dedicado a la homogeneidad del corpus y a la filiación de las variantes textuales, y otro a las transformaciones intertextuales en que se establece la fórmula canónica del modelo «fuerte», del modelo «débil» y la fórmula canónica del corpus extenso (transformaciones, inversión del contenido e inversión de las funciones, homologaciones e isomorfismo).

El apartado de la disertación dedicado al análisis semiótico contiene la organización sintagmática de los micro-relatos, las configuraciones discursivas, las secuencias, los motivos y las llamadas «secuencias móviles». Este desbroce permite la descripción del nivel semio-narrativo en su triple aspecto:

a) semántica y sintaxis fundamentales (categorías semánticas y axiología; procedimientos de desemantización y resemantización); 
b) el nivel narrativo de superficie (isotopías y organización del micro-universo de significación en el corpus de base; sintaxis actancial, programas y recorridos narrativos, dimensiones pragmática y cognoscitiva del relato; sintaxis superficial) y

c) el nivel discursivo que integra a las organizaciones actorial y espacial.

Termina esta segunda parte con la relación de los elementos para un modelo narrativo que incluye el tema general $\longrightarrow$ ideología en sentido estricto-, las constantes obtenidas, la coherencia y compatibilidad narrativa de los relatos. Merced a la precisión teórico-metodológica del análisis semiótico sobre la verosimilitud discursiva así realizada, se consigue obtener algunos criterios relativamente ajustados para tipologizar los relatos de literatura oral ancestral y popular peruanos cuyos límites, en el caso de otras literaturas orales producidas por sociedades similares a la andina, no han sido fijados aún hoy día.

Algunos otros estudios cierran esta panorama de la literatura oral peruana bajo la perspectiva semiótica. El primero es un análisis del mito andino de la "Achiquée», a partir de once variantes, realizado por R. Bueno y D. Blanco (1980), al cual se adjuntó el relato de «Mama Galla» según R. Bueno (1978). Debe destacarse en estos dos estudios solidarios el afán por distinguir con rigor semántico la oposición mítica andina / mítica cristiana tratada en los estudios antropológicos y religiosos con preconceptos trascendentalistas. En este proyecto se consolidó la isotopía temática del conjunto original del corpus narrativo y se aclaró la participación de otras isotopías figurativas, todo lo cual justificó postular una posible interpretación analógica entre la semiótica de la lengua natural y la semiótica del mundo natural sin la consabida participación interdisciplinaria de la antropología. El análisis de S. López (1981) se aplica luego a una leyenda tradicional del folclore de Cajamarca, en el norte del Perú; sin embargo, al carecerse de datos etnológicos para reforzar la interpretación, ella se limita a describir la organización del enunciado.

Pero como anotáramos en 2.2.1, buena parte de los semióticos peruanos que iniciaron sus estudios en este campo de conocimientos se inclinaron por investigar los productos de la cultura oral popular como lo hiciera T. Silva (1972) en su memoria de maestría o los textos de literatura oral ancestral. Éste es el caso de los relatos transcritos en las crónicas peruanas de los siglos XVI y XVII estudiados por R. Quispe $(1984,1987)$ en el marco de los motivos etnoliterarios. Siguiendo los principios de estructuración propuestos por J. Courtés, Quispe logró establecer una breve tipología de adquisición del «objeto origen» por parte del sujeto de estado y luego averiguó la estructura modal de dichos motivos, especialmente el de la «conquista», lo que le per- 
mitió abordar con cierta fortuna la naturaleza semántica del discurso de la historia y sus categorías reiteradas: «objetividad», «verosimilitud», «persuasión», etc.

M. Jara (1988) emprendió el análisis de la categoría «agua» en la cosmovisión andina mediante un conjunto de microrrelatos tomados del Manuscrito de Huarochirí en sus versiones quechua y española. Su propósito fue el estudio exhaustivo de los recorridos figurativos y de las configuraciones discursivas capaces de definir un conjunto de valores semánticos propios de la identidad ancestral peruana. A. G. Fuentes (1988) ha dedicado también sus esfuerzos al estudio detallado de la etapa final del programa narrativo - la sanción - en la extensa crónica de Felipe Guamán Poma de Ayala. En efecto, allí se trató de describir las funciones semánticas que ejerce el enunciador-juez y sus enunciados judicatorios a fin de conocer los valores ideológicos con que manifiestamente obraron los conquistadores españoles en el manejo político y administrativo de su colonia andina.

C. Rubina $(1989,1990,1992,1995,1999)$ y C. Zanelli $(1989,1992,1996$, 1999a, 1999b) prosiguieron las investigaciones en este mismo marco de estudios. La primera puso a prueba los esquemas semióticos que abarcan la totalidad del programa generativo (estructuras profundas y de superficie) descrito en un relato concreto consignado en el Manuscrito de Huarochirí. Los valiosos resultados de este procedimiento analítico se justificaron ampliamente al haberse logrado destacar buena parte de las restricciones axiológicas de la narrativa oral ancestral andina, en especial las atinentes a una figura clave, la "piedra». De semejantes alcances es el trabajo de C. Zanelli sobre el ciclo mítico de Pariaca propuesto como un «análisis de linguística del discurso». Por primera vez se aborda allí la estructura general de un ciclo mítico, aprovechando los beneficios de la descripción semiótica vinculada a los motivos narrativos. Cabe destacar, en este sentido, el examen de las estructuras de recepción y de la evolución discursiva del héroe a manera de hilo ensamblador de los motivos que componen un ciclo mítico, además del acercamiento al discurso ritual en tanto vivencia sociolinguiística del grupo social que lo produce.

En una vía distinta a las tesis mencionadas, E. Huarag (1982) publicó un manual para el estudio de los relatos orales producidos por la sociedad andina e hizo especial incidencia en determinar los componentes mítico-religioso y religioso-moral de los valores semánticos. Su ensayo trató de explicar la inserción de las formaciones discursivas ancestrales en las formaciones socio-económicas actualmente vigentes en los Andes Centrales. Los análisis de R. Bueno (1984b) y E. Ballón Aguirre (1983a, 1986h, 1991a, 1992a, 1992b, 1994d, 1995a, 1995b, 1995c, 1997a, 1998b, 1999a) en esta materia se 
ocuparon más bien de los relatos etnoliterarios provenientes de los sociolectos andinos y amazónicos, revelando su distinta naturaleza discursiva frente a los relatos clasificados como pertenecientes a la literatura oral popular peruana. En estos análisis recientes y a través de numerosos corpus de literatura oral ancestral, se explora la posibilidad de establecer un catálogo de motivos relativamente preciso merced a la clasificación de temas y figuras persistentes en la gran tradición literaria oral de la zona.

\subsubsection{Ensayo}

El examen semiótico de los ensayos poéticos y políticos del escritor César Vallejo ha tenido varias etapas (Ballón Aguirre, 1973a, 1977c, 1981b, 1982b, 1985a): desde la primera de orden exploratorio, la segunda que contó con la aplicación de la metodología de la lingüística de la comunicación a una crónica periodística y la tercera que comprendió a más de doscientos cincuenta ensayos (crónicas) de Vallejo, todo bajo un dispositivo organizado a partir de la linguística del discurso y la semiótica de la Escuela de París.

En el ensayo tentativo inicial se conformó el corpus de base poniendo en juego la heurística y la hermenéutica filológica que exigía el caso. Las aproximaciones a los textos tanto de orden lingüístico como semiótico posteriores aprehendieron la problemática global de la escritura ensayística comenzando por establecer la producción, circulación y consumo de los textos en las circunstancias histórico-sociológicas de su redacción. Como la finalidad perseguida era poner en claro la evolución que experimentaron los valores ideológicos contenidos en las crónicas vallejianas entre 1915 y 1938 , la primera tarea fue dilucidar la tipología semántica de los enunciados portadores de los discursos político y poético. En seguida, desde una perspectiva diacrónica y siguiendo el eje fundamental de la estructura isotópica de cada discurso, se circunscribieron las etapas ideológicas del discurso ensayístico integral, sus variaciones, los accidentes del compromiso que asume el enunciador frente a sus enunciatarios en cada oportunidad, esto con el fin de lograr un perfil coherente sobre los cambios que ocurren en los valores de significación incorporados en la competencia del enunciador. En el trayecto mencionado se corrigen los innumerables juicios críticos dedicados a la escritura de Vallejo, juicios por lo general intuitivos y contradictorios carentes de una regulación sistemática consecuente.

Con esta investigación se inició en la semiótica peruana la aproximación a los textos no figurativos y se enmarcó el área dirigida a evaluar el control (o descontrol) ejercido a través de los valores de conocimiento manipulados en los discursos de las llamadas «humanidades», sus enunciados de «verdad», 
las operaciones de «convencimiento» y argumentación, sus regímenes de probanza y comprobación, etc., en especial los criterios de «probanza» con que operan los discursos de la crítica literaria peruana todavía hoy en boga. El análisis semiótico se constituyó a sí mismo en tanto metatexto de segundo grado, metatexto que tuvo por textos de base los discursos de crítica literaria considerados en cuanto metatextos de primer grado, mientras que los textos literarios originales, motivo de la crítica, fueron tenidos como pre-textos de referencia respecto del análisis semiótico.

Los valores semánticos de orden psicológico en los textos literarios y los escritos de San Agustín fueron decantados a la luz de la metodología semiótica por D. Blanco $(1986,1989)$. Las obras de San Agustín, como se sabe, han sido citadas frecuentemente en la historia de esta disciplina e incluso son tomadas como punto de partida para relanzar ciertos temas de teoría semiótica (A. Rey, U. Eco, etc.), pero esos mismos textos no habían sido estudiados semióticamente en cuanto tales. Blanco saca partido oportuno de esa carencia y los interpreta obteniendo así algunos de los principales esquemas categoriales en el pensamiento agustiniano.

\subsubsection{Traducción}

Los semióticos peruanos se han enfrentado a un primer problema de traducción: fijar la terminología semántica y semiótica en lengua española. A este respecto, J. L. Rivarola recibió el encargo de K. Baldinger y K. Heger para traducir sus obras ${ }^{24}$ y luego E. Ballón Aguirre y H. Campodónico, con la colaboración de B. Pottier, tradujeron Semiótica-Diccionario razonado de la teoría del lenguaje 25 a solicitud de sus autores A. J. Greimas y J. Courtés. El segundo volumen fue traducido por E. Ballón Aguirre (1986i, 1986j) que también es autor de las 19 entradas redactadas especialmente para la versión española de ese diccionario. Prosiguiendo esta misma labor de traducción de las obras capitales de la Escuela de París, E. Ballón Aguirre (1993b, 1994e, 1995h) tradujo el conocido manual introductorio de J. Courtés y la obra que A. J. Greimas y J. Fontanille dedicaran a la semiótica de las pasiones. En todos estos casos se trató de regularizar los neologismos en lengua española empleados ya por entonces en el metalenguaje semántico y semiótico alemán, francés e inglés.

La segunda tarea fue dedicada a aprovechar lo que podríamos llamar la «utilería» semiótica para resolver los problemas de traducción que plantea

24 Se trata de las obras de Kurt Baldinger, Teoría Semántica (Hacia una semántica moderna). Madrid: Alcalá, 1977 y de Klaus Heger, Teoria Semántica (Hacia una semántica moderna) II. Madrid: Alcalá, 1974.

25 Fue publicado en Madrid: Editorial Gredos S.A., 1982. 
el habla y escritura diglósica peruana. E. Ballón Aguirre (1987b, 1994a) como director durante varios años del Programa de Traducción del Departamento de Lenguas y Literaturas de Arizona State University y el lingüista R. Cerrón Palomino (1992, en prensa) profesor de la Pontificia Universidad Católica del Perú han dedicado sus esfuerzos en ese sentido. Ambas perspectivas sobre la aprehensión semiótica de los fenómenos de traducción motivaron a algunos estudiosos para continuar tal labor: por ejemplo, M. Radulescu (1988), que desde una visión panorámica teórica y metodológica plantea una serie de propuestas semióticas precisas para observar los principales problemas de traducción; L. Fossa $(1987,1988)$ se refiere a la utilidad de los postulados semióticos para la traducción de textos heteroglósicos desde la competencia localizada del enunciador y su manifestación en los enunciados textuales; R. Quispe (1988) expone ciertos conceptos elegidos del modelo de la Escuela de París pertinentes, en su criterio, para analizar convenientemente el contenido de los textos traducidos y, finalmente, $F$. Arango Ramos (1995) que luego de una amplia revisión teórico-metodológica se ocupa del arduo problema de la traducción de textos etnoliterarios, con el propósito de sugerir la aplicación de ciertos principios del conocimiento semiótico susceptibles de superar los tradicionales escollos en esta materia.

\subsubsection{Comunicación de masas}

Una disertación de V. Bueno (1972) inicia la aplicación de la metodología semiótica a los medios de comunicación masiva. Con ocasión del asesinato del magnate de la pesca en el Perú L. Banchero, la prensa nacional construyó su biografía - una verdadera hagiografía - cuyos mecanismos narrativos son analizados en la tesis de Bueno con el fin de mostrar los mecanismos persuasivos cuando se crean los «héroes de prensa». Se trata de un estudio académico puesto al servicio de la desmitificación de los contenidos transmitidos por los relatos periodísticos.

La publicación colectiva de diversos trabajos semióticos, dedicados a la comunicación de masas en 1973, promovió una visión menos mecanicista y empírica sobre la comunicación tal como entonces se practicaba ${ }^{26}$. Dos trabajos, uno de R. León (1973) sobre la publicidad televisada y otro de A. González (1973) sobre los valores ideológicos subliminales en un texto de dibujos animados, mostraron en qué medida el análisis semiótico es capaz no sólo de describir de modo preciso el contenido textual sino de apoyar la

26 Aparecieron en la revista Textual, n. 8. Lima: Instituto Nacional de Cultura del Perú. 
denuncia sobre la producción, transmisión y recepción de los valores dominantes. Este mismo propósito alentó el examen icónico de un afiche publicitario sobre la «historia del Perú» realizado por Ballón Aguirre (1973b) y otro referido a ciertos bienes de consumo cotidiano por D. Blanco y R. Bueno (1980), pero han sido R. M. de los Heros con la colaboración de I. Banchero quienes ha incidido notablemente en este campo con nueve crónicas dedicadas a explicar en forma concreta la manipulación ideológica al tomar contacto esas dos macrosemióticas que son el mundo natural (o naturalizado por la cultura) y las lenguas naturales en la representación visual 27 .

La articulación de la lingüística de la comunicación y la semiótica de la cultura ha servido a E. Ballón Aguirre (1975, 1976, 2001b) para, en primer lugar, plantear una hipótesis sobre el «contrato pedagógico» y la preservación de los valores de la cultura tradicional establecidos por la institución escolar peruana; en segundo lugar para estudiar los efectos que produce en el Perú el impacto de la televisión como instrumento de dominación - persuasión y convencimiento- de los grupos marginados en el país, particularmente sobre los hablantes bilingües quechuahispanos. Estos tópicos han sido reexaminados recientemente a la luz de la situación actual de la educación peruana en todos sus niveles, desde la escolarización inicial hasta la educación superior.

Siempre en el campo de la comunicación de masas, O. Quezada (1979, 1981, 1983, 1988b, 1999b) ha aplicado numerosas categorías semióticas al análisis de los artículos periodísticos escritos y difundidos en el Perú. Los textos estudiados contienen temas tales como la acción política de los gobiernos militares, las posturas editoriales expresadas a través de caricaturas, el discurso paródico de las revistas humorísticas, los resúmenes anuales de noticias (sus reflexiones y previsiones), el llamado "periodismo cultural», etc. A ello se agrega últimamente su preocupación por los discursos sobre la conservación del medio ambiente. Gracias al examen de todos estos discursos se muestra cómo el estudio semiótico es capaz de aguzar la competencia ideológica —ética y política- de los trabajadores en comunicación de masas. De modo similar, R. Sheen (1984) analizó una misma noticia en dos diarios de tendencias ideológicas antagónicas. Esta tesis de excelente factura pedagógica presenta un cotejo detallado de los valores semánticos descritos, sus enfrentamientos o sus colusiones, demostrando los regímenes ideológicos que presiden la construcción de la

27 La serie tuvo el título general «Cosas y signos» y apareció en la página editorial del diario La Crónica de Lima con los siguientes títulos y fechas: «La ilusión tiene otro nombre» (31/10/74), «El país de las maravillas» (12/11/74), «Para anestesiar las frustraciones» $(26 / 11 / 74)$, «Una profesión lucrativa» (12/12/74), «Absurda imagen de la eficiencia» (7/1/75), «Servicio o lucro?» $(12 / 2 / 75)$, «El vals es nuestro» $(22 / 2 / 75) \mathrm{y}$ «Olor de la ciudad» $(14 / 3 / 75)$. 
noticia periodística ${ }^{28}$. D. Blanco ${ }^{29}$ reunió, por último, un conjunto bastante amplio de noticias periodísticas a fin de estudiar la constitución de un imaginario: Europa en las noticias cotidianas de los diarios. Allí observó los patrones ideológicos que gobiernan a las agencias noticiosas (Reuter, UPI, EFE, etc.) para producir una ilusión referencial sobre la realidad y la historia cotidiana de esa parte del mundo y demostró que la «coherencia» de las figuraciones y los juicios periodísticos depende de la manipulación y las operaciones de convencimiento ejercido por esos enunciadores «objetivos».

Las telenovelas de factura peruana y latinoamericana que invaden las pantallas domésticas sugirieron a R. Bueno (1981) un análisis relativamente integral, tema que fue igualmente estudiado por O. Quezada (1989), pero desde una perspectiva más concreta: la elaboración de las narraciones televisadas. R. Bendezú (1985a, 1985b, 1987a, 1987b) trató de explicar los alcances semióticos de la televisión a través del estudio de los programas y la publicidad ${ }^{30}$, sobre todo los mecanismos de persuasión con que se manipula al televidente y en cuanto a la llamada «comunicación alternativa» el enfoque se circunscribió a los problemas de «concientización» derivados de la dimensión discursiva de los mensajes, dimensión más que olvidada, trivializada, en los trabajos empíricos de los «comunicadores sociales» peruanos al tratar la cultura popular.

Un texto importante de D. Blanco (1989: 293-316) dio cuenta de la relación entre la nueva tecnología y los «lenguajes de comunicación» destacándose en especial las tecnologías de producción (video, los hologramas y la televisión tridimensional), de difusión (comunicación por satélite y satélite de difusión directa, fibras ópticas) y de consumo (video-grabadora, videodisco y video-texto). Esta primera exploración semiótica de los nuevos medios de comunicación ofrece un campo de estudio prometedor, especialmente ahora que la informática revoluciona los conceptos tradionales de la comunicación de masas.

28 D. Ackerman (1986) se ocupa de la sección «correo sentimental» de los medios de comunicación de masas y sus discursos caracterizados por actualizar situaciones emotivas. La naturaleza testimonial e histórica (individual) de este tipo de discursos fue aprovechada para destacar los valores de cultura popular que obra en ellos, valores en contrapunto con las fotonovelas y las telenovelas. Sin embargo, este trabajo no alzanzó el rigor semiótico deseable.

29 En D. Blanco (1989:91-136;317-392) los artículos (1986) «Roles actanciales de los trabajadores en el discurso periodístico de izquierda», Contratexto 2; (1988) «Imagen de Europa en los medios de comunicación del Perú», Cuadernos de CICOSUL 7.

${ }^{30}$ La publicidad no ha merecido la atención de los semióticos peruanos, al menos en la misma medida que la dedicada por los semióticos de otros países del continente (Argentina, Brazil, México, etc.). No obstante, la citada revista Textual 8 (1973) tuvo como tema central la publicidad y O. Quesada (1979) ha hecho una investigación en ese sentido. 


\title{
3. CONVERGENCIAS INTERDISCIPLINARIAS
}

\subsection{Semiótica y Antropología}

La cooperación interdisciplinaria constantemente mencionada, pero rara vez llevada a la práctica con la sindéresis profesional deseable, fue el propósito declarado de un número de la revista Amazonía Peruana ${ }^{31}$. A través del examen de algunos relatos orales ancestrales, pertenecientes a las etnias aguaruna y yagua de la selva peruana, la investigación semio-antropológica tuvo en cuenta, según Ballón Aguirre (1978a):

\begin{abstract}
el análisis previo de las condiciones y relaciones de producción de los textos, es decir, su conocimiento riguroso y especifico en el momento histórico de su registro, lo cual permite evitar los contrasentidos, la explotación consciente o inconsciente de los temas y las estructuras simbólicas de los mitos. Sobre todo este último aspecto debe ser evitado en la aplicación de las ciencias sociales en vista del análisis de las ideologías, de los sistemas (socializados) de los símbolos de un grupo social dado y en el estudio de sus relaciones con los universos imaginarios correspondientes. La evolución de los grandes sistemas socializados de símbolos míticos, nos remite sin cesar a la evolución del conjunto de las relaciones sociales histórica y espacialmente situadas.
\end{abstract}

La interdisciplinaridad semio-antropológica se hizo, entonces, indispensable en el estudio de la eficacia simbólica de los mitos, de su relación con los combates ideológicos, con la evolución de las necesidades económico-culturales y la salvaguarda y enriquecimiento crítico de la herencia cultural de los grupos sociales peruanos inmersos en el fenómeno del multilingüismo y la pluricultura. Al tratar de compatibilizarse los procedimientos de una y otra disciplina, se optó por una operación inductivo-deductiva, preservándose en todo momento la distinción entre los campos de estudio de cada una e integrando ambos conocimientos sin reducir una disciplina a la otra, por ejemplo, se empleó el control semiótico para la interpretación del relato, pero la determinación de los rasgos sémicos en la constitución de los sememas sólo pudo ser realizado merced al conocimiento contextual proporcionado por el análisis antropológico. Esta precaución evitó la posible interferencia de los paradigmas congnoscitivos de cada disciplina, cosa que sin duda hubiera producido un serio contratiempo teórico-metodológico.

La aplicación de la interdisciplina la hicieron E. Ballón Aguirre y M. García-Rendueles Fernández (1978) sobre un corpus constituido por variantes

31 Revista Amazonía Peruana II, 3 (1978), 234. 
del mito de Núnkui. Una vez lograda la organización secuencial del relato, se procedió a su examen en cuatro apartados fundamentales. El primero de ellos comprendió la tipología del relato, el segundo la estructura actancial y actorial, el tercero se ocupó de los valores antropológicos y la lectura semiótica del relato (estructuras profunda y superficial); finalmente, el cuarto apartado se dedicó a la proyección etno-semiótica del mito. Los halagadores resultados obtenidos con la mencionada experiencia abrieron un camino por el que ha transitado prácticamente toda la investigación posterior en ese área de conocimiento interdisciplinario: por ejemplo, el trabajo de campo de G. Brero sobre los relatos orales en jakaru, un dialecto de los Andes Centrales, de E. Fernández en la etnia campa, de O. Adauto entre los lamas, de $\mathrm{S}$. Latorre en las comunidades aborígenes del Cuzco, de I. Chonati en la Provincia de Yauyos, de E. Espinoza en la etnia machiguenga, etc.

\subsection{Semiótica y Derecho}

El primer análisis de un texto jurídico realizado por un semiótico peruano es el aplicado al Proyecto de ley relativo a la interrupción de la gestación (aprobado por el Consejo de Ministros de Francia el 6 de junio de 1973) que hiciera el abogado R. Carrión en el Seminario de Semántica General, dirigido por el profesor A. J. Greimas en la École des Hâutes Études en Sciences Sociales de París, el 16 de abril de 1975. Luego de un examen de las modalidades lógico-deónticas de este texto, se procedió a describir la sintaxis de la estructura superficial en relación a las modalidades que obran en la competencia de cada actor respecto de la actancia desempeñada, especialmente la modalidad del «deber» descrita con apoyo en la metodología lógico-jurídica y semiótica.

A partir de esta primera aproximación a la problemática semio-jurídica, Carrión (1977) proyectó una semiótica jurídico-lingüística en la que

una perspectiva diferente del lenguaje jurídico debería considerar como objeto principal de estudio la constitución semántica del discurso juridico; como es obvio, toda constitución apunta a un proceso. Describir este proceso por medio del cual se constituye el discurso jurídico como un discurso autónomo y a la vez dependiente, determinando así su propio universo semántico y sus rasgos formales diferenciadores, es la primera tarea a emprender. Como el sentido de esta investigación semiótica no es el mismo de las semióticas jurídicas lógica y analitica ¿cuál es, entonces, el propósito metodológico de una semiótica jurídica lingüística? (...): el problema que consideramos fundamental y que a lo largo del desarrollo de la ciencia jurídica ha tomado varias formas y diferentes propuestas de solución el de la significación de los discursos jurídicos en la práctica efectiva del derecho [itálicas en el original.] 
Este esbozo ha sido ampliado por R. Carrión (1981), que, no obstante su reducida repercusión inmediata, dejó abierta una vía de investigación cada vez más importante.

\section{PERSPECTIVAS}

La práctica de la disciplina semiótica en el Perú durante más de tres décadas ha acumulado, por lo visto, una amplia y robusta experiencia que hoy le permite avizorar el futuro en pie de igualdad - y en algunos casos con algo de ventaja - a la práctica semiótica de otras sociedades, especialmente latinoamericanas. Una preocupación constante de la semiótica peruana ha sido y es la búsqueda de planteamientos tanto teóricos como metodológicos para responder a los desafíos de la producción cultural de esta sociedad multilinguie y pluricultural, heredera de un inmenso acervo ancestral aborigen y una tradición de contacto occidental que pasa largo los cuatrocientos cincuenta años. Es justamente en ese crucero cultural en el que la semiótica peruana tiene, sin duda, su mejor oportunidad de presentar verdaderos aportes a la reflexión de la comunidad semiótica internacional. En efecto, cada vez se confirma, con mayor evidencia, que la originalidad de las investigaciones peruanas depende en gran medida de la respuesta dada a los retos que le presenta dicha propiedad raigal de la sociedad peruana.

Afianzada ya en buena medida la cobertura institucional del saber semiótico, su ejercicio disciplinario quedará asegurado en la medida en que se prosiga ahondando en las vías abiertas, pero también emprendiendo el conocimiento de los campos todavía no hollados. A su buen logro contribuirán las aperturas epistemológicas que ofrecen, sobre todo, la lingüística del discurso, la teoría de la enunciación, la informática, la lógica categorial, la semántica interpretativa y diferencial y hasta la matemática de catástrofes. Sin distender en ningún momento la coherencia y rigor que caracterizan al núcleo fuerte del saber semiótico, el contacto con estos conocimientos vecinos, cada vez más prometedores, vivificará sin duda las reflexiones sobre los significados y sentidos resultantes de la continua controversia entre los componentes culturales que ensamblan la identidad nacional peruana.

\section{Referencias bibliográficas}

ACKerman, D. (1986). Aproximación semiótica a «Casos del corazón». Tesis de Bachiller. Lima: Universidad de Lima, Facultad de Ciencias de la Comunicación. 
ARANGo RAmOS, F. (1995). «Algunos criterios utilizados en la traducción de etnoliteratura». Escritos 11/12, 357-379.

- (1996). Paradigma de la prosa poética de César Vallejo. Disertación de Ph. D. Phoenix: Arizona State University, Department of Languages \& Literatures.

Ballón AguiRre, E. (1969). Idéologie, critique et création chez César Vallejo. Tesis de Diplomado en Ciencias Sociales. París: École Pratique des Hâutes Études, VIème. Section.

- (1971). Vallejo como paradigma (un caso especial de escritura). Tesis de Doctor en Literatura. Lima: Universidad Nacional Mayor de San Marcos.

- (1972). «Una lectura semiológica del poema V de Trilce de César Vallejo». En Literatura de la Emancipación y otros ensayos (Memoria del IV Congreso del Instituto Internacional de Literatura Iberoamericana), 158-168. Lima: Universidad Nacional Mayor de San Marcos.

- (1973a). La poétique de César Vallejo. Tesis de Docteur de Troisième Cicle en Semiótica Lingüística. París: Université de París III (Sorbonne Nouvelle) y École Pratique des Hâutes Études, Vİ̀me. Section.

- (1973b). «El icono de la Historia del Perú». Textual 8, 70-76.

- (1974a). Vallejo como paradigma (un caso especial de escritura). Lima: Instituto Nacional de Cultura del Perú. 2. ed. (1986) Puebla (México): Universidad Autónoma de Puebla.

- (1974b). «La interrogante en la poética de Vallejo». En Julio Ortega (ed.), César Vallejo, 469-478. Madrid: Taurus Ediciones.

- (1975). «Diálogo e información I y II». Lima: La Crónica, 25 y 28 de febrero.

- (1976). Comunicación colectiva y lenguajes oprimidos en el Perú. Lima: Universidad Nacional Mayor de San Marcos, Departamento de Lingüística.

- (1977a). «Respuesta a "Relectura de Trilce 5"». Dispositio - Revista Hispánica de Semiótica Literaria II, 5-6, 226-238.

- (1977b). «Textología y metafrasis». Dispositio - Revista Hispánica de Semiótica Literaria II, 5-6, 239-252.

- (1977c). «César Vallejo en viaje a Rusia». Hispamérica 18, 3-30.

- (1977d). «Vallejo: escritura e intertexto». Runa 2, 32-33.

- (1978a). «Editorial». Amazonía Peruana II, 3, 3-4.

- (1978b). «Introducción al estudio semiótico de la literatura étnica en el Perú». Amazonía Peruana II, 3, 53-98.

- (1978c). «Vallejo/Eguren». En Lingüística y Educación (Actas del IV Congreso Internacional de la Asociación de Lingüística y Filología de América Latina), 209-220. Lima: Universidad Nacional Mayor de San Marcos.

- (1979a). «Para una definición de la escritura de César Vallejo». En E. Ballón Aguirre (ed., pról.y cron.) César Vallejo, Obra Poética Completa, IX-LXXVII. Caracas: Biblioteca Ayacucho 58.

- (1979b). Ed., pról. y cron. en César Vallejo, Obra Poética Completa. Caracas: Biblioteca Ayacucho 58.

- (1979c). Ed., pról. y not. en César Vallejo, Teatro Completo I y II. Lima: Pontificia Universidad Católica del Perú.

— (1981). «Poética del intersticio». Lexis V, 1, 147-169. Rep. en D. W. Foster y D. 
Altamiranda (eds.), Spanish American Literature. A Collection of Essays 4. Twentieth-Century Spanish American Literature to 1960. Hamden, CT: Garland Publishing.

- (1982a). «Literatura y política en el pensamiento de César Vallejo». Socialismo y Participación 20, 43-59.

- (1982b). «La escritura poetológica: César Vallejo cronista». Lexis VI, 1, 57-98.

- (1983a). «Notas sobre el motivo "origen" (en el Manuscrito de Huarochirí" s. XVII)». Teoría Semiótica. Lenguajes y Textos Hispánicos (Actas del Congreso Internacional sobre Semiótica e Hispanismo) I, 821-837. Madrid: Consejo Superior de Investigaciones Científicas. Rep. en (1983) Quillqa I, 1, 27-43.

- (1983b). «Multiglosia y poder de expresión en la sociedad peruana». En A. Corbera (ed.), Educación y Lingüística en la Amazonía Peruana, 10-22. Lima: Centro Amazónico de Antropología y Aplicación Práctica.

- (1984-1985). Ed., pról. y notas en César Vallejo Crónicas I y II. México: Universidad Nacional Autónoma de México.

- (1985a). Poetología y escritura - Las crónicas de César Vallejo, 3 vols. México: Universidad Nacional Autónoma de México.

- (1985b). «L'état tendu de l'action». En H. Parret y H. G. Ruprecht (eds.), Aims and Perspects of Semiotics - Essays in honor of Algirdas Julien Greimas. Exigences et perspectives de la sémiotique - Recueil d' hommages pour A. J. Greimas, I, 113-121. Amsterdam/Philadelphia: John Benjamins Publishing Co. Trad. esp. (1986) «El estado tenso de la acción». Acta Poética 6, 41-51. Rep. en (1986) Escritos I, 1, 37-47 y en (1987) Cuicuilco 18, 86-91.

- (1985c). «Introducción a la lexicografía en lenguas andinas y selváticas». Amazonía Peruana VI, 12, 59-115.

- (1985d). «El discurso de la crítica literaria». Contratexto 1, 16-28.

- (1986a). «Semiotics in Perú». En The Semiotic Sphere, Thomas A. Sebeok Jean Umiker Sebeok (ed.), 387-405. New York and London: Plenum Press. Trad. esp. (1981) «La Semiótica en el Perú». Apuntes VI, 11, 39-59.

- (1986b). «Intracultura e intercultura, enseñanza de lenguas y elucidación literaria». En Coloquio Mundo Latinoamericano y Mundo de Habla Francesa, enseñanza, comunicación y representación, 223-233. México: AUPELF, UDUAL, UNAM.

- (1986c). «Las modalidades sustantivas». En Actas del II Congreso Internacional sobre el Español de América, 618-627. México: Facultad de Filosofía y Letras de la Universidad Nacional Autónoma de México. Rep. en (1986) Lexis $\mathrm{X}, 2,169-186$.

- (1986d). «Lenguas, literaturas y discursos: la multiglosia peruana». En E. Yepes (ed.), Estudios de Historia de la Ciencia en el Perú II, 1-39. Lima: Consejo Nacional de Ciencias y Tecnología - Sociedad Peruana de Historia de la Ciencia y la Tecnología.

- (1986e). Antología general de la prosa en el Perú - De 1895 a 1985, III. Lima: Ediciones Edubanco.

- (1986f), «El discurso de la historia de la literatura peruana». Socialismo y Participación 33, 65-82. 
- (1986g). «Política linguopedagógica peruana». Revista Andina 4, 2, 479-499.

- (1986h). «El motivo "creación" (del hombre) en la mítica de los Huitoto». Amazonía Peruana VII, 13, 91-101.

- (1986i). Traducción de A. J. Greimas y J. Courtés, Semiótica - Diccionario razonado de la teoría del lenguaje II. Madrid: Editorial Gredos S. A.

- (1986j). Entradas en A. J. Greimas y J. Courtés, Semiótica - Diccionario razonado de la teoría del lenguaje II: «Desustantivación», «Ectópico (espacio)», «Esencia semiótica», «Estar», «Existencia semiótica», «Fingimiento B», «Halotácticas (Modalidades)», «Heterotópico (espacio)», «Localización espacio-temporal», «Modalidad A, B», «Objetivación», «Persuasivo (hacer)», «Preterición (existencia por)», «Ser», «Subjetivación B», «Sustantivación», «Sustantivas (modalidades)», «Tensión A», «Tópico (espacio)».

- (1987a). «Lengua, escritura y comunicación literaria (notas introductorias)». Apuntes 21, 99-106. Rep. con variantes en (1986) Aproximaciones a la narrativa. Lima: Salvat - Ministerio de Educación.

- (1987b). «Traducir al castellano desde el Perú». T' ikray I, 1, 11-16.

- $(1987 \mathrm{c})$. «Contenidos etnográficos y culturales en la educación bilingüe». Allpanchis Phuturinqa XIX, 29-30, 309-325.

- (1987d). «De lo figurativo a lo figural (Nota 1)». Lienzo 7, 287-296.

- (1987e). «Una encrucijada entre filología, lingüística y semiótica: el corpus». Dispositio - Revista Hispánica de Semiótica Literaria XII, 30-32, 45-64.

- (1987f). «Historiografía de la literatura en sociedades plurinacionales (multilingües y pluriculturales) - Un escorzo». Filología XXII, 2, 5-25.

- (1988a). «Hare (una técnica fotográfica)». Contratexto 5, 157-179.

- (1988b). «"Intervención”- Mesa Redonda: La Traducción Literaria y sus escollos». En Actas del Primer Encuentro Nacional de Traductores, I, 135-142. Lima: Universidad Ricardo Palma - Universidad Femenina Sagrado Corazón.

- (1988c) «El efecto ideológico en el teatro de César Vallejo: "Colacho Hermanos o Presidentes de América"». Cuadernos Hispanoamericanos 454-455, 423448.

- (1988d). La cultura peruana - César Vallejo. Lima: Mosca Azul Editores.

- (1989a). «José Carlos Mariátegui y César Vallejo: una correspondencia». Anuario Mariateguiano I, 1, 135-150.

- (1989b). «La identidad lingüística y cultural peruana: bilingüismo y diglosia». En L. E. López, I. Pozzi-Escot, M. Zúñiga (eds.), Temas de Lingüística Aplicada. Actas del $1^{\text {er }}$ Congreso Nacional de Investigaciones Lingüístico-Filológicas, 77-93. Lima: Consejo Nacional de Ciencia y Tecnología - Programa de Educación Bilingüe de Puno.

- (1989c). «Los acrósticos de César Vallejo». Escritos 5, 75-97. Rep. con variantes en (1999) Fronteras de la Semiótica, 347-388. Lima: Universidad de Lima Fondo de Cultura Económica, Perú.

- (1990a). «Semiotics in Perú 1980-1989». En The Semiotic Web 1989, Thomas A. Sebeok - Jean Umiker Sebeok (ed.), 253-301. Berlin and New York: Mouton de Gruyter. Trad. esp. (1989) «La semiótica en el Perú 1980-1989». Lienzo 9, 165-194. 
- (1990b). «Las diglosias literarias peruanas (deslindes y conceptos)». En E. Ballón Aguirre y R. Cerrón Palomino (eds.), Diglosia linguo-literaria y educación en el Perú - Homenaje a Alberto Escobar, 253-301. Lima: Consejo Nacional de Ciencia y Tecnología - Convenio Perú - RFA (GTZ).

- (1991a). «Etnoliteratura andina: el motivo Desafío». Anthropologica IX, 9, 73-96.

- (1991b). Traducción de A. J. Greimas y J. Courtés, Semiótica - Diccionario razonado de la teoría del lenguaje II. Madrid: Editorial Gredos S. A.

- (1992a). «Etnoliteratura y literatura oral peruanas». Mester XXI, 2, 109-131.

- (1992b). «Un motivo etnoliterario andino: la Deslealtad». Escritos 8, 86-101.

- (1993a). «Las Academias peruanas de las lenguas». Socialismo y Participación 64, 83-90.

- (1993b). Traducción de M. Kajman y C. Lesnes «Una entrevista con Algirdas Julien Greimas». Acciones Textuales 4-5, 3, 3-11.

- (1994a). «Metastabilidad interpretativa en la traducción de la poesía vallejiana». En Vallejo - Su tiempo y su obra. Actas del Coloquio Internacional, agosto 25-28 de 1992, 427-466. Lima: Universidad de Lima.

- (1994b). «Valores y valencias en la narrativa de José Carlos Mariátegui». Anuario Mariateguiano VI, 6, 145-167.

- (1994c). «Nuevas reflexiones sobre las modalidades sustantivas». Escritos 10, 139-150.

- (1994d). «Etiología jíbara I: origen de la monogamia, del zapallo, de la arcilla y de las manchas de la luna». Amazonía Peruana XII, 24, 11-76.

- (1994e). Revisión de la traducción de A. J. Greimas y J. Fontanille, Semiótica de las pasiones - De los estados de cosas a los estados de ánimo. México: Editorial Siglo XXI.

- (1995a). «Nota sobre la aspectualidad temporal y espacial en etnoliteratura». Escritos 11-12, 303-355.

— (1995b). «Etiología jíbara II: origen de la alfarería». Amazonía Peruana XIII, $2,9-74$.

- (1995c). «Identidad y alteridad en un motivo etnoliterario amerindio e indoeuropeo: la doncella fecundada». Revista Andina 13, 1, 43-81.

- (1995d). «Respuesta». Revista Andina 13, 1, 92-102.

- (1995e). Edición de Escritos 10/11: «Tradición oral hispánica y etnoliteratura amerindia». Puebla: Universidad Autónoma de Puebla.

- (1995f). «Dedicatoria». Escritos 11-12, 9-15.

- (1995g). «La literatura oral en Latinoamérica: una hipótesis semiolingüística». Escritos 11-12, 17-34.

- (1995h). Traducción de J. Courtés, «Etnoliteratura, retórica y semiótica - De los "motivos" a los "topoi"». Escritos 11-12, 303-355.

- (1996). «Procedimientos discursivos en una epístola-poema colonial (a propósito de cierta carta de un minero peruano a una monja mexicana, siglo XVII)». En J. Pascual Buxó (ed.), La cultura literaria en la América Virreinal, Concurrencias y Diferencias, 43-99. México: Universidad Nacional Autónoma de México. 
- (1997a). «Mito y rito: linderos y puentes discursivos en el Manuscrito de Huarochiri'). Anthropologica XV, 15, 305-326.

- (1997b). Traducción de J. Courtés, Análisis semiótico del discurso - Del enunciado a la enunciación. Madrid: Editorial Gredos S. A.

- (1998a). «Los corresponsales peruanos de Sor Juana». En M. Glantz (ed.), Sor Juana Inés de la Cruz y sus contemporáneos, 139-199. México: Facultad de Filosofía y Letras de la Universidad Nacional Autónoma de México, Centro de Estudios de Historia de México (CONDUMEX). Rep. en (1997) Lexis XXI, 2, 273-325.

- (1998b). «Identidad y alteridad en la etnoliteratura amerindia e indoeuropea». En P. Horwath (ed.), Humanism and the Good Life. Proceedings of the Fifteenth Congress of the World Federation of Humanists, 539-554. New York: Peter Lang.

- (1998c). «Prólogo». En A. M. Fernández Lávaque y J. del Valle Rodas (comps.), Español y quechua en el norte argentino. Contactos y transferencias, 13-14. Salta: Universidad Nacional de Salta.

- (1998d). «Censuras coloniales peruanas: la obra atribuida a Juan del Valle y Caviedes». Caliope IV, 1-2, 107-124. Rep. en (1998) Lexis XXII, 1, 11-33 y en (1999) G. Sabat de Rivers (ed.), Ésta, de nuestra América pupila: estudios de poesía colonial, 107-124. Houston: Society for Renaissance \& Baroque Hispanic Poetry.

- (1998e). «Los incidentes objetivantes del discurso subjetivo (rudimentos de una investigación)». En J. Pascual Buxó (ed.), Sor Juana Inés de la Cruz y las vicisitudes de la crítica, 133-159. México: Universidad Nacional Autónoma de México. Rep. en (1999) Boletín de la Academia Peruana de la Lengua 31, 95129.

- (1999a). «Literatura popular oral peruana». En J. C. Godenzzi Alegre (comp.), Tradición oral andina y amazónica. Métodos de análisis e interpretación de textos, 291-337. Cuzco: Centro de Estudios Regionales Andinos «Bartolomé de las Casas» - Programa de Formación en Educación Intercultural Bilingüe para los Países Andinos (PROEIB-ANDES).

- (1999b). «Formación de la Institución Literaria Peruana». Hueso Húmero 35, 183-189.

- (1999c). «Desconcierto barroco». Revista Andina 33, 17, 1, 163-234.

- (1999d). «Cuenta y razón: los texos atribuidos a Juan del Valle y Caviedes (un siglo de ediciones)». Lexis XXIII, 2, 359-399.

- (1999e). Traducción de C. Vallejo, Lock-Out. Lima: Pontificia Universidad Católica del Perú.

- (2001a). Desconcierto barroco. México: Universidad Nacional Autónoma de México.

- (2001b). «La intercultura peruana: lenguas, literaturas y educación». En M. Heise (comp. y ed.), Interculturalidad - Creación de un concepto y desarrollo de una actitud, 239-280. Lima: Programa Marco de Formación Profesional Tecnológica y Pedagógica en el Perú (FORTE-PE) - Ministerio de Educación del Perú. 
- (En prensa). Los corresponsales peruanos de Sor Juana y otras digresiones (ensayos).

- (En prensa). Literatura oral peruana.

- (En prensa). «Montezuma de Federico II el Grande, rey de Prusia».

- (En prensa). «Crónica de una dolencia vindicada».

- (En prensa). «Literatura oral ancestral peruana».

- (En prensa). «Evolución léxica y área enunciva de un vocablo quechua: papa».

- (En prensa). «Joglería colonial peruana: de crepitus ventris y halitus poeticus».

- (En prensa). «Semántica y léxico agrario andino».

- (En prensa). «Literatura oral peruana: una hipótesis discursiva».

- (En prensa). «Autour des typologies lexicales (texte, cotexte et contexte dans les clasifications onomasiologiques des taxonomies ancestrales)».

- (En prensa). «Procedimientos discursivos en una carta romanceada (a propósito de cierta misiva de un minero peruano a una monja mexicana, siglo XVII Nueva versión)».

Ballón AguirRe, E. y Ballón AguiRre, J. (1995). «Comparative American Ethnoliterature: the Challenge Motif». Poetics Today 16, 1, 29-51.

Ballón Aguirre, E. y CAMPOdónico, H. (1976). «Relato oral en el Perú - Legibilidad y valores». En Actes du XLII'é. Congres International des Américanistes IV, 405-433. Rep. con variantes en (1977) Allpanchis Phuturinqa X, 10, 137-174.

- (1982). Traducción de A. J. Greimas y J. Courtés, Semiótica - Diccionario razonado de la teoría del lenguaje. Madrid: Editorial Gredos S. A.

Ballón Aguirre, E. y CerRón-Palomino, R. (1990), Diglosia linguo-literaria y educación en el Perú - Homenaje a Alberto Escobar. Lima: Consejo Nacional de Ciencia y Tecnología (CONCYTEC) - Convenio Perú-RFA (GTZ).

- (En prensa). Terminología agraria andina (Nombres quechumaras de la papa). Cuzco: International Potato Center - Centro de Estudios Regionales Andinos «Bartolomé de las Casas».

Ballón Aguirre, E.; Cerrón-Palomino, R. y Chambi Apaza, E. (1992). Vocabulario razonado de la actividad agraria andina - Terminología quechua. Cuzco: Centro de Estudios Regionales Andinos «Bartolomé de las Casas».

Ballón Aguirre, E.; Cisneros, L. J.; Franco, C. y Klaiber, J. (1986). César Vallejo: ideólogo y político. Lima: Universidad del Pacífico.

Ballón AguiRre, E.; EsCobAR, A. y Millones, L. (1986). Antología general de la prosa en el Perú I y II. Lima: Ediciones Edubanco.

Ballón AgutrRe, E. y García-Rendueles Fernández, M. (1978). «"Núnkui” y la instauración del orden social civilizado». Amazonía Peruana II, 3, 99-158.

Ballón AGUIRRE, E. y RIvera RodAs, O. (eds.) (en prensa). Literatura y cultura novohispana - Homenaje Internacional a José Pascual Buxó. México: Universidad Nacional Autónoma de México.

Ballón Aguirre, E. y Salazar Bustamante, F. (1983). «Estructura elemental de la significación "espacio" (Trilce de César Vallejo)». En Crítica Semiológica de Textos Literarios Hispánicos (Actas del Congreso Internacional sobre Semiótica e Hispanismo) II, 887-904. Madrid: Consejo Superior de Investigaciones Científicas. Rep. con variantes en (1996) Garrido Gallardo, M. Á. (ed.), La 
Moderna Crítica Literaria Hispánica. Antología, 311-331. Madrid: Editorial MAPFRE.

BENDEZÚ, R. (1985a). Masividad y educación. Análisis semiótico del discurso didáctico audiovisual "Plaza Sésamo». Tesis de Bachiller. Universidad de Lima, Facultad de Ciencias de la Comunicación.

- (1985b). «Publicidad y televisión: la puesta en discurso. Análisis semiótico de un spot televisivo de "Mercedes Benz"). Cuadernos del CICOSUL 2.

- (1987a). El discurso de la comunicación alternativa: una aproximación semiótica. Tesis de Licenciatura. Universidad de Lima, Facultad de Ciencias de la Comunicación.

- (1987b). «Discurso y acción social. Aproximación semiótica a la comunicación alternativa». I Congreso Latinoamericano de Semiótica: de la práctica a la teoría. Rosario (Argentina): 5-8 de octubre.

- (1999). «El diagnóstico semiótico en la planificación estratégica de comunicaciones de marketing». En Quesada, Ó. (ed.), Fronteras de la semiótica - Homenaje a Desiderio Blanco, 281-296. Lima: Universidad de Lima - Fondo de Cultura Económica, Perú.

Blanco, D. (1974a). «"Gritos y susurros": la penúltima angustia de Igmar Bergman». Hablemos de cine 66.

- (1974b). «Tristana o la circularidad lineal». Hablemos de cine 68.

- (1976). «"Escenas de la vida conyugal”: estética e ideología». Hablemos de cine 78.

— (1977a). «Problemática educativa de los medios de comunicación social». Medios 1.

- (1977b). «El realizador frente a su obra». Medios 1 .

- (1980a). «Comunicación y sociedad». Scientia y praxis 14.

- (1980b). «Nuevos aportes para "ver" el cine». Crónica Cultural 4.

- (1980c). «El sentido y la fuerza». Crónica Cultural 8.

- (1985). «Posibilidades y límites de la semiótica». Chasqui 15.

- (1986). «Claves semióticas para una lectura del pensamiento de san Agustín». En San Agustín y la liberación. Reflexiones desde Latinoamérica. Lima: CETA/CEP.

- (1987). Imagen por imagen. Teoría y crítica cinematográfica. Lima: Universidad de Lima.

- (1988). «Figuras discursivas de la enunciación cinematográfica». Lienzo 8, 269-311. Trad. esp. de (1987) Actes Sémiotiques - Documents X, 90.

- (1989). Claves semióticas. Comunicación/Significación. Lima: Universidad de Lima.

Blanco, D. y BuENo, R. (1978). «"La niña de la lámpara azul”: fundamentos de una lectura plural». Hispamérica 20.

- (1980). Metodología del análisis semiótico. Lima: Ediciones de la Universidad de Lima.

BuENO, R. (1976). «Lectura semiológica de un poema de García Lorca». Letras 84-85, 202-215.

- (1978). «"Mama Galla": las figuras del mal en un relato andino». Revista de Crítica Literaria Latinoamericana 7-8, 93-103. 
- (1979). «Borges y la fobia crepuscular». Cielo abierto 2.

- (1981). «La telenovela latinoamericana: el gesto en acción». Caracas: El Nacional, sup. El papel literario, 20 de diciembre.

- (1983a). «Sobre la nueva novela y la nueva crítica latinoamericana». Revista de Crítica Literaria Latinoamericana 18, 81-85.

- (1983b). «Notas sobre el concretismo brasileño». Texto Crítico 26-27, 236-240.

- (1984a) «De la noche profunda a la luz cenital en la poesía de Joaquim Cardozo». En Joaquim Cardozo: poemas. Lima: Centro de Estudios Brasileños.

- (1984b). «Lectura social de relatos andinos: "El lagarto" y otros cuentos de Lucanamarca». Revista de Crítica Literaria Latinoamericana 20, 9-28.

- (1985a). «Necesidad y sentido de una teoría de la literatura latinoamericana». Pukio 2, 24-29. Rep. con variantes en (1988) Latin America: New Directions in Literary Theory and Criticism. New Hampshire: Dartmouth College.

- (1985b). Poesía hispanoamericana de vanguardia. Procedimientos de interpretación textual. Lima: Latinoamericana Editores.

- (1986a). «El relato como aventura intelectual: Borges y el problema de la identidad de los personajes». Lexis X, 2, 229-235.

— (1986b). «Literaturas y críticas en el Perú de hoy». La República, 38-39, 28 de junio.

- (1986c). «Escribir en Hispanoamérica: escribir Hispanoamérica». Revista de Crítica Literaria Latinoamericana 23, 103-113.

- (1987). «El perfil de un perfil. Ensayo sobre la poesía de Edgard Guzmán». En Guzmán, E. Perfil de la materia, 7-38. Arequipa: Publiunsa.

- (1988a). «Planteamientos de la actual crítica literaria latinoamericana». Letras 90.

- (1988b). «Prólogo». En Medina, L. Los muros de la ciudad. Arequipa: Conciertos de la Gran Flauta.

- (1999). «La salvación por el cuerpo: sentido de la poesía de Desiderio Blanco». En Quesada, Ó. (ed.), Fronteras de la semiótica - Homenaje a Desiderio Blanco, 473-484. Lima: Universidad de Lima - Fondo de Cultura Económica, Perú.

BUENo R. y PASTOR B. (1988). «Introducción a la nueva conciencia crítica latinoamericana». En Actas del Coloquio "Latin America: New Directions in Literary Theory and Criticism». New Hampshire: Darmouth, Hanover.

BuENo, V. (1972). «Absurdo fin de un triunfador» (Mito y semantización ideológica en un relato de prensa). Tesis de Bachiller. Lima: Universidad Nacional Mayor de San Marcos, Programa Académico de Literaturas Hispánicas.

CAMPODÓNICO, H. (1978). «Definiciones y clasificaciones en la lengua natural Doxología y configuración sémica». Lexis, II, 2, 165-199.

- (1980). Littérature orale du Nord du Pérou: approche sémiotique I, II. Tesis para obtener el grado de Docteur de Troisième Cycle en Semiótica Lingüística. París: Université de Paris III (Sorbonne Nouvelle) y École des Hâutes Études en Sciences Sociales.

- (1985). «Taxinomies paysannes: problématique sémiotique». En H. Parret y H. G. Ruprecht (eds.), Aims and Perspects of Semiotics - Essays in honor of Algirdas Julien Greimas. Exigences et perspectives de la sémiotique - Recueil 
d'hommages pour A. J. Greimas, I, 423-433. Amsterdam/Philadelphia: John Benjamins Publishing Co.

CARrión, R. (1977). «Elementos de semiótica jurídica». Anuario 1977, 260-320. Rep. con variantes en (1978) Historia, problema y posibilidad, II, 17-43. Lima: Pontificia Universidad Católica del Perú.

- (1981). «Los elementos semióticos del derecho». Investigaciones Semióticas, I, 1.

Cuculiza, M. N. (1995). «Intervención». Revista Andina 13, 1, 82-83.

DAÑINo, G. (1972). El universo significado de «Rondinelas» de José María Eguren. Tesis de Doctor. Lima: Pontificia Universidad Católica del Perú, Programa de Letras y Ciencias Humanas.

- (1976). «Semiótica de la imagen artística». Letras 84-85, 5-15.

- (1980). «Semiótica». Cielo abierto IV, 10.

Escobar, A. (1974). «Prólogo». En Ballón Aguirre, E. (1974) Vallejo como paradigma (un caso especial de escritura), 7-13. Lima: Instituto Nacional de Cultura.

- (1981). «Lectura de Vallejo: mitificación y desmitificación». En Actas de la Mesa Redonda sobre César Vallejo, 19-40. Tübingen: Freie Universität Berlin, Niemeyer Verlag.

- (1984). Arguedas o la utopía de la lengua. Lima: Instituto de Estudios Peruanos.

- (1988a). «Una pregunta pendiente». Lima: El Comercio, sup. Dominical 8, 10 de abril.

- (1988b). «Discurso de orden en el centenario de la muerte de César Vallejo». Lima: Academia Peruana de la Lengua.

- (1989). El imaginario nacional: Moro-Westphalen-Arguedas, una formación literaria. Lima: Instituto de Estudios Peruanos.

FossA, L. (1987). «Informe: el "Seminario sobre las perspectivas y proyecciones de la semiótica" de Herman Parret en la Universidad de Lima - 1986». T' ikray 1, 173-175.

- (1988). «Informe sobre el Taller de traducción del inglés al español». Actas del Primer Encuentro Nacional de Traductores II, 241-259. Lima: Universidad Ricardo Palma - Universidad Femenina Sagrado Corazón.

Fuentes, A. G. (1988). La "sanción» en la «Primer Nueva Corónica y Buen Gobierno» de Felipe Guaman Poma de Ayala. Tesis de Bachiller. Lima: Pontificia Universidad Católica del Perú, Programa de Letras y Ciencias Humanas.

GAZZOLO, A. M. (1974). Estructura actancial de base en «El zorro de arriba y el zorro de abajo» de José María Arguedas. Tesis de Bachiller. Lima: Universidad Nacional Mayor de San Marcos, Programa Académico de Literaturas Hispánicas. GodeNZZI, J. C. (1995). «Discurso y actos de rebelión anticolonial: textos políticos del siglo XVIII en los Andes». En Itier, C. (comp.), Del Siglo de Oro al siglo de las luces. Lenguaje y sociedad en los Andes del Siglo XVIII, 59-88. Cuzco: Centro de Estudios Regionales Andinos «Bartolomé de las Casas».

GonzÁlez, A. (1972). López Albujar: de lo verosímil práctico a lo verosímil mítico. Tesis de Bachiller. Lima: Universidad Nacional Mayor de San Marcos, Programa Académico de Literaturas Hispánicas. 
— (1973). «"Bugs Bunny en el U. S. Army”: azar o coincidencia ideológica». Textual 8, 56-62.

GUTIÉRREZ, C. (1976). Verosímil histórico y verosímil narrativo en «Bajo el signo de la Mariscala» de F. Vegas Seminario. Tesis de Bachiller. Lima: Pontificia Universidad Católica del Perú, Programa de Letras y Ciencias Humanas.

HEROS, R. M. DE LOS (1972). Estructura cíclica de base en "Cien años de soledad» de Gabriel García Márquez. Tesis de Bachiller. Lima: Pontificia Universidad Católica del Perú, Programa de Letras y Ciencias Humanas.

- (1975). La temporalidad del relato en "Cien años de soledad». Tesis de Doctor. Lima: Pontificia Universidad Católica del Perú, Programa de Letras y Ciencias Humanas.

HuARAG, E. (1974a). Análisis estructural del cuento «Al pie del acantilado». Tesis de Bachiller. Lima: Pontificia Universidad Católica del Perú, Programa de Letras y Ciencias Humanas.

- (1974b). Rasgos pertinentes en un relato de Ribeyro. Tesis de Doctor. Lima: Pontificia Universidad Católica del Perú, Programa de Letras y Ciencias Humanas.

- (1980). Estudio semiológico sobre el neo-realismo. Ayacucho: Universidad Nacional de San Cristóbal de Huamanga. Textos Universitarios 2.

- (1982). Introducción al estudio del relato oral. Ayacucho: Universidad Nacional de San Cristóbal de Huamanga.

— (1985). «“¿Por qué vive el añás debajo de la tierra?”. Análisis didáctico para el curso de Análisis de Mensajes» (separata). Lima: Facultad de Ciencias de la Comunicación de la Universidad de Lima.

JARA, M. (1988). La categoría «agua» en la cosmovisión andina (valores semánticos e identidad cultural). Tesis de Bachiller. Lima: Pontificia Universidad Católica del Perú, Programa de Letras y Ciencias Humanas.

JUAN SAURA, M. (1988). L' espace dans «El zorro de arriba y el zorro de abajo» de José María Arguedas. Tesis de Doctorado. Montréal: Université de Québec à Montréal, Département d'Études Littéraires.

LEón, R. (1973). «Las funciones del lenguaje en la publicidad televisada». Textual 8, 32-39.

LERNER, R. (1987). El discurso subjetivo en "Vida exagerada de Martín Romaña» de Alfredo Bryce Echenique. Memoria de Maestría. Lima: Pontificia Universidad Católica del Perú, Programa Académico de Letras y Ciencias Humanas.

LóPEZ, S. (1981). Aproximación semiótica a un relato oral cajamarquino. Tesis de Bachiller. Lima: Universidad Nacional Mayor de San Marcos, Programa Académico de Literatura.

- (1999). «De lo nítido a lo borroso: la representación del Perú en "7 ensayos de interpretación de la realidad peruana"». En Quesada, Ó. (ed.), Fronteras de la semiótica - Homenaje a Desiderio Blanco, 297-307. Lima: Universidad de Lima - Fondo de Cultura Económica, Perú.

MARTÍNEZ, G. (1987). Una mesa ritual en Sucre - Aproximación semiótica al ritual andino. La Paz: Hisbol-Asur.

QUESADA, Ó. (1979). «Hay placeres que pueden evitarse (formaciones imaginarias 
y discurso publicitario)», separata. Lima: Universidad de Lima, Facultad de Ciencias de la Comunicación.

- (1980). «En torno al significante estético». Lienzo 1.

- (1981). Aproximación semiótico-ideológica a las caricaturas editoriales del diario "El Comercio» 1977-1980. Tesis de Licenciatura. Universidad de Lima, Facultad de Ciencias de la Comunicación.

- (1983). «La visión de "Visión". Semiótica del discurso editorial». Contratexto $1,105-150$.

- (1986). «Electoralidad: dispositivo formal y efecto (afecto) del sentido». Contratexto 2, 139-182.

- (1988a). «Modalización epistémica y paradoja espacial en el poema "Un sueño" de Borges». Lienzo 8, 111-144.

- (1988b). «Semiótica y comunicación social en el Perú». En Diálogos de la Comunicación 22, 14-27. Lima: FELAFACS.

- (1989). «Sujetos y estereotipos de la mediación espectacular en la teleinformación. El caso de El Sexto». II Foro Internacional de Comunicación Social: Comunicación y violencia. Cuadernos del CICOSUL.

- (1999a). «Presentación». En Quesada, Ó. (ed.), Fronteras de la semiótica Homenaje a Desiderio Blanco, 9-23. Lima: Universidad de Lima - Fondo de Cultura Económica, Perú.

- (1999b). «La pasión de la conservación: poder y medio ambiente». En Quesada, Ó. (ed.), Fronteras de la semiótica - Homenaje a Desiderio Blanco, 309343. Lima: Universidad de Lima - Fondo de Cultura Económica, Perú.

QUISPE, R. (1984). Estructura del microrelato: el motivo «origen» en las crónicas de Fray Martín de Murúa (S. XVI y XVII). Tesis de Bachiller. Lima: Pontificia Universidad Católica del Perú, Programa de Letras y Ciencias Humanas.

- (1987). Motif et Configuration: la "conquete» dans la chronique de F. Martín de Murúa. Memoire D.E.A. Sciences du Langage. Toulouse: Université de Toulouse II - Le Mirail, U.E.R. Linguistique.

- (1988). «La traducción y el modelo de análisis semiótico de textos: aproximaciones». Ponencia presentada en el Seminario sobre Teoría del texto aplicado a la traducción, celebrado en la Facultad de Lenguas Modernas de la Universidad Ricardo Palma, Lima.

RAdULESCO, M. (1988). «Análisis del discurso en una semiótica de la traducción». En Actas del Primer Encuentro Nacional de Traductores I, 23-43. Lima: Universidad Ricardo Palma - Universidad Femenina Sagrado Corazón.

RAMírez, U. (1972). Del icono de Leonardo de Vinci a la iconografía de César Vallejo. Tesis de Bachiller. Lima: Pontificia Universidad Católica del Perú, Programa de Letras y Ciencias Humanas.

- (1996). «"El amar su propia muerte" de Juan Espinosa Medrano y la dramaturgia del Siglo de Oro (Apuntes para un estudio)». En Pascual Buxó, J. (ed.), La Cultura Literaria en la América Virreinal. Concurrencias y Diferencias, 299316. México: Universidad Nacional Autónoma de México.

- (En prensa). «Jael y Sisara: figuras simbólicas». 
REIsZ, S. (1976). «Poética y lingúística: en torno a las teorías de R. Jakobson, M. Riffaterre y J. Lotman». NRFH XXV, 73-83.

- (1977a). «Poetische Aquivalenzen. Grundverfahren dichterischer Gestaltung bei Catull». Beihefte zu Poetica, Heft 13.

- (1977b). «Predicación metafórica y discurso simbólico. Hacia una teoría de dos fenómenos semiótico-literarios». Lexis I, 1, 51-99.

- (1979). «Ficcionalidad, referencia, tipos de ficción literaria». Lexis III, 2, 99170.

- (1980a). «Borges: teoría y práctica de la ficción fantástica». VII Congreso de la Asociación Internacional de Hispanistas (Venecia).

- (1980b). «La literatura como mímesis. Apuntes para la historia de un malentendido». III Coloquio Internacional de Poética y Semiología Literaria, México.

- (1980c). «Transferencias poéticas: Garcilaso de la Vega y su "imitación" de la bucólica virgiliana». Iberoromania VI, 86-121.

- (1981). «La posición de la lírica en la teoría de los géneros literarios». Lexis V, 1.

- (1986). Teoría literaria. Una propuesta. Lima: Pontificia Universidad Católica del Perú.

Rivarola, J. L. (1978a). «Monosemismo y polisemismo. Algunas observaciones sobre el problema de la unidad del signo». Lexis II, 2, 253-266.

- (1978b). «El español medieval. Algunos aspectos de la formación del español como lengua literaria». Revista de la Universidad Católica 4, 321-333.

RIVAROLA, J. L. y BALDINGER, K. (1974). «Designaciones del concepto de "tonto" en la América Española». En Estudios filológicos y lingüísticos (Homenaje a Ángel Rosemblat), 59-81. Caracas: Instituto Pedagógico.

Rivarola, J. L. y ReIz, S. (1984). «Semiótica del discurso referido». En Schartz Lerner, L. y Lerner, I. (eds.), Homenaje a Ana María Barrenechea, 151-174. Madrid: Castalia.

RochA, A. M. (1972). El espacio y la significación de «5 metros de poemas» de Carlos Oquendo de Amat. Tesis de Bachiller. Lima: Pontificia Universidad Católica del Perú, Programa de Letras y Ciencias Humanas.

RuBINA, C. (1989). Estructura significativa del relato mítico en "Una tradición sobre Cuniraya Huiracocha". Tesis de Bachiller. Pontificia Universidad Católica del Perú, Programa de Letras y Ciencias Humanas.

- (1990). Analyse sémiotique de la configuration «petrification» dans le Manuscrit de Huarochirí. Mémoire de Maîtrise en Sciences du Langage. Toulouse: Université de Toulouse-Le Mirail.

- (1992). «La petrificación en el Manuscrito de Huarochirí»». Mester XII, 2, 71-82.

- (1995). «La piedra "incaychu": una configuración discursiva». Escritos 11/12, 285-302.

- (1999). Analyse sémiotique du motif de la "pierre» dans le Manuscrit de Huarochirí. Thèse de Doctorat en Sciences du Langage. Toulouse: Université de Toulouse-Le Mirail.

Ruz, L. (1972). Análisis de la estructura base de la relación actancial en «Un mundo para Julius». Tesis de Bachiller. Lima: Pontificia Universidad Católica del Perú, Programa de Letras y Ciencias Humanas. 
- (1973). La paradoja de un relato. Tesis de Doctorado. Lima: Pontificia Universidad Católica del Perú, Programa de Letras y Ciencias Humanas.

RuPRECHT, H. G. «Pour un projet de "Théorie de la littérature"». Dispositio Revista Hispánica de Semiótica Literaria II, 7-8, 219-142. Rep. Documents de Travail. Centro Internazionale de Semiotica e di Linguistica. Urbino: Universitá di Urbino.

SalazAR Bustamante, F. (1995). «Intervención». Revista Andina 13, 1, 84-86.

SHEEN, R. (1984). Aproximación semiótica al análisis del discurso masivo sobre el terrorismo en Ayacucho. Tesis de Bachiller. Universidad de Lima, Facultad de Ciencias de la Comunicación.

SILVA, T. (1972). La evasión y otras constantes axiológicas en la obra de Felipe Pinglo. Tesis de Bachiller. Lima: Pontificia Universidad Católica del Perú, Programa de Letras y Ciencias Humanas.

STÖCKINGER, P. (1980). Die Französische Schule der Semiotik. Aspecte einer generative theorie der Semiotik. Dissertation zen Erbangung des Doktor-grades. Salzburg: Universität Salzburg, Philosophischen Fakultät.

VARIOS AUTORES. (1981). Literatura y sociedad en el Perú. Lima: Hueso Húmero Ediciones.

ZANelli, C. El ciclo mítico de Pariacaca (análisis en lingüistica del discurso). Tesis de Bachiller. Pontificia Universidad Católica del Perú, Programa de Letras y Ciencias Humanas.

- (1992). «Tiempo y utopía en las primeras representaciones del mundo andino». Mester XXI, 2, 97-108.

- (1995). «Intervención». Revista Andina 13, 1, 89-92.

- (1996). «La dimensión trágica de la Historia: el caso de Gonzalo Pizarro en la Historia general del Perú del Inca Garcilaso de la Vega». En Pascual Buxó, J. (ed.), La Cultura Literaria en la América Virreinal. Concurrencias y Diferencias, 351-360. México: Universidad Nacional Autónoma de México.

- (1999a). «Formas e ideas de lo trágico en la Historia general del Perú del Inca Garcilaso». En Hampe Martínez, T. (comp.), La tradición clásica en el Perú virreinal, 157-172. Lima: Fondo Editorial de la Universidad Nacional Mayor de San Marcos.

- (1999b). «La Virgen María y la síntesis de contradicciones en los Comentarios reales (segunda parte)». En Silva Santisteban, R. (comp.), El combate de los ángeles. Literatura, género, diferencia, 79-95. Lima: Pontificia Universidad Católica del Perú.

- (En prensa). «Cultura indígena e impronta femenina en dos loas de Sor Juana Inés de la Cruz». 